\title{
Production of methyl vinyl ketone and methacrolein via the hydroperoxyl pathway of isoprene oxidation
}

\author{
Y. J. Liu ${ }^{1}$, I. Herdlinger-Blatt ${ }^{1,2}$, K. A. McKinney ${ }^{3}$, and S. T. Martin ${ }^{1,4}$ \\ ${ }^{1}$ School of Engineering and Applied Sciences, Harvard University, Cambridge, Massachusetts, USA \\ ${ }^{2}$ Institute of Ion Physics and Applied Physics, University of Innsbruck, Innsbruck, Austria \\ ${ }^{3}$ Department of Chemistry, Amherst College, Amherst, Massachusetts, USA \\ ${ }^{4}$ Department of Earth and Planetary Sciences, Harvard University, Cambridge, Massachusetts, USA
}

Correspondence to: K. A. McKinney (kamckinney@amherst.edu) and S. T. Martin (scot_martin@ harvard.edu)

Received: 1 December 2012 - Published in Atmos. Chem. Phys. Discuss.: 21 December 2012

Revised: 22 April 2013 - Accepted: 23 April 2013 - Published: 14 June 2013

\begin{abstract}
The photo-oxidation chemistry of isoprene (ISOP; $\mathrm{C}_{5} \mathrm{H}_{8}$ ) was studied in a continuous-flow chamber under conditions such that the reactions of the isoprene-derived peroxyl radicals $\left(\mathrm{RO}_{2}\right)$ were dominated by the hydroperoxyl $\left(\mathrm{HO}_{2}\right)$ pathway. A proton-transfer-reaction time-offlight mass spectrometer (PTR-TOF-MS) with switchable $\mathrm{H}_{3} \mathrm{O}^{+}$and $\mathrm{NO}^{+}$reagent ions was used for product analysis. The products methyl vinyl ketone $\left(\mathrm{MVK} ; \mathrm{C}_{4} \mathrm{H}_{6} \mathrm{O}\right)$ and methacrolein (MACR; $\mathrm{C}_{4} \mathrm{H}_{6} \mathrm{O}$ ) were differentiated using $\mathrm{NO}^{+}$reagent ions. The MVK and MACR yields via the $\mathrm{HO}_{2}$ pathway were $(3.8 \pm 1.3) \%$ and $(2.5 \pm 0.9) \%$, respectively, at $+25^{\circ} \mathrm{C}$ and $<2 \%$ relative humidity. The respective yields were $(41.4 \pm 5.5) \%$ and $(29.6 \pm 4.2) \%$ via the NO pathway. Production of MVK and MACR via the $\mathrm{HO}_{2}$ pathway implies concomitant production of hydroxyl $((6.3 \pm 2.1) \%)$ and hydroperoxyl $((6.3 \pm 2.1) \%)$ radicals, meaning a $\mathrm{HO}_{\mathrm{x}}$ recycling of $(12.6 \pm 4.2) \%$ given that $\mathrm{HO}_{2}$ was both a reactant and product. Other isoprene oxidation products, believed to be mostly organic hydroperoxides, also contributed to the ion intensity at the same mass-to-charge $(\mathrm{m} / \mathrm{z})$ ratios as the MVK and MACR product ions for $\mathrm{HO}_{2}$-dominant conditions. These products were selectively removed from the gas phase by placement of a cold trap $\left(-40^{\circ} \mathrm{C}\right)$ inline prior to the PTR-TOF-MS. When incorporated into regional and global chemical transport models, the yields of MVK and MACR and the concomitant $\mathrm{HO}_{\mathrm{x}}$ recycling reported in this study can improve the accuracy of the simulation of the $\mathrm{HO}_{2}$ reaction pathway of isoprene, which is believed to be the fate of approximately half of atmospherically produced isoprenederived peroxy radicals on a global scale.
\end{abstract}

\section{Introduction}

By abundance, isoprene (ISOP; $\mathrm{C}_{5} \mathrm{H}_{8}$ ) is the dominant nonmethane biogenic volatile organic compound (VOC) in the atmosphere, and its reactive chemistry plays an important role in the oxidative cycles of the atmosphere (Poisson et al., 2000). Isoprene oxidation is typically initiated by the addition of a hydroxyl radical $(\mathrm{OH})$ across a double bond followed by rapid reaction of the alkyl radical with molecular oxygen $\left(\mathrm{O}_{2}\right)$, resulting in the production of a series of isomeric hydroxyl-substituted alkyl peroxyl radicals (ISOPOO; $\mathrm{HOC}_{5} \mathrm{H}_{8} \mathrm{OO} \cdot$ ) (Fig. 1). The subsequent chemistry of the ISOPOO radicals proceeds along several competing pathways: (i) reactions with nitric oxide (NO) (e.g., Tuazon and Atkinson, 1990), (ii) reactions with hydroperoxyl radicals $\left(\mathrm{HO}_{2}\right)$ (e.g., Paulot et al., 2009), (iii) self- and cross-reactions with other organic peroxyl radicals $\left(\mathrm{RO}_{2}\right)$ (Jenkin et al., 1998), and (iv) possible unimolecular isomerization reactions (Peeters et al., 2009; da Silva et al., 2010; Crounse et al., 2011). For atmospheric conditions, the $\mathrm{NO}$ and $\mathrm{HO}_{2}$ pathways are the major competing reaction pathways affecting the fate of ISOPOO (Crounse et al., 2011). The reaction with NO dominates in polluted, urban regions of the planet. Many isoprene source regions, particularly remote tropical forests, have sufficiently low $\mathrm{NO}_{\mathrm{x}}$ concentrations (e.g., Lelieveld et al., 2008; Hewitt et al., 2010) that the $\mathrm{HO}_{2}$ pathway dominates. The $\mathrm{HO}_{2}$ pathway is estimated to account globally for one half of the reactive fate of ISOPOO (Crounse et al., 2011). 
There remain significant uncertainties in the branching ratios and principal products of isoprene photo-oxidation for the $\mathrm{HO}_{2}$ reaction pathway. Mechanisms employed in many regional and global models, including the near-explicit Master Chemical Mechanism (MCM v3.2) (Jenkin et al., 1997; Saunders et al., 2003), treat the reaction of $\mathrm{HO}_{2}$ with ISOPOO as a radical-termination reaction, as follows:

$\mathrm{ISOPOO}+\mathrm{HO}_{2} \rightarrow \mathrm{ISOPOOH}+\mathrm{O}_{2}$

in which organic hydroperoxides (ISOPOOH; $\mathrm{HOC}_{5} \mathrm{H}_{8} \mathrm{OOH}$ ) are formed with $100 \%$ yield. A competing, less investigated pathway, however, might also be important (Dillon and Crowley, 2008) (Reaction R1b):

$\mathrm{ISOPOO}+\mathrm{HO}_{2} \rightarrow \mathrm{ISOPO}+\mathrm{OH}+\mathrm{O}_{2}$

This pathway produces alkoxy radicals (ISOPO, $\left.\mathrm{HOC}_{5} \mathrm{H}_{8} \mathrm{O}^{*}\right)$ and $\mathrm{OH}$. Given that the oxidation pathway was initiated by $\mathrm{OH}$ attack on isoprene, the production of $\mathrm{OH}$ implies a recycling of the reactant. This type of reaction has been demonstrated in the laboratory for some organic peroxyl radicals (Sulbaek Andersen et al., 2003; Hasson et al., 2004; Jenkin et al., 2007, 2008; Dillon and Crowley, 2008). Theoretical studies suggest that this reaction is favored for peroxyl radicals having the forms RCHXOO and $\mathrm{RCHXCH}_{2} \mathrm{OO}$ that can pass through a hydrotetroxide intermediate, where $\mathrm{X}$ is an electronegative atom (Hasson et al., 2005). The internal hydrogen bonding between the hydrotetroxide and atom X lowers the transition state energy. Two ISOPOO isomers, namely ISOPBOO and ISOPDOO, accounting together for $75 \%$ of ISOPOO based on the MCM, have this chemical form (Fig. 1).

Methyl vinyl ketone (MVK, $\mathrm{C}_{4} \mathrm{H}_{6} \mathrm{O}$ ) and methacrolein (MACR, $\mathrm{C}_{4} \mathrm{H}_{6} \mathrm{O}$ ) can be produced by the decomposition of the ISOPBOO and ISOPDOO isomers, as follows (cf. Fig. 1):

$\mathrm{ISOPBO} \stackrel{\mathrm{O}_{2}}{\longrightarrow} \mathrm{MVK}+\mathrm{HCHO}+\mathrm{HO}_{2}$

$\mathrm{ISOPDO} \stackrel{\mathrm{O}_{2}}{\longrightarrow} \mathrm{MACR}+\mathrm{HCHO}+\mathrm{HO}_{2}$

Radical termination by Reaction (R1a) does not produce MVK or MACR. Hence, the yields of MVK and MACR can serve as tracers for the occurrence of Reaction (R1b). The experimental strategy of the present study is to take advantage of MVK and MACR as indicators of Reaction (R1b), compared to Reaction (R1a), to assess the importance of the former as a reaction channel of ISOPOO with $\mathrm{HO}_{2}$. Furthermore, $\mathrm{HO}_{2}$ is also a product of Reaction (R1b) followed by Reactions (R2) and (R3), implying a recycling of this reactant. Taken together, Reactions (R1b), (R2), and (R3) indicate possible significant recycling of the $\mathrm{HO}_{\mathrm{x}}$ family in this reaction sequence.

The isoprene photo-oxidation experiments described herein were conducted in a continuous-flow chamber. Efforts were made to ensure and to verify that the $\mathrm{HO}_{2}$ pathway

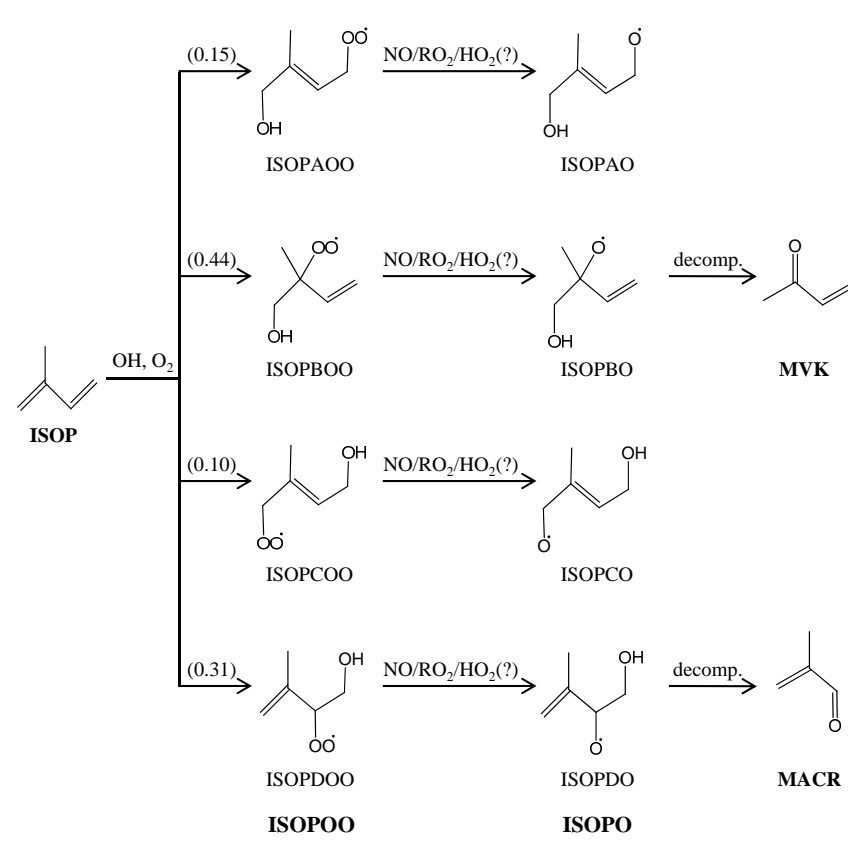

Fig. 1. Mechanism of isoprene oxidation to produce MVK and MACR as first-generation products. Results are shown for NO and $\mathrm{RO}_{2}$ pathways, as represented in MCM v3.2. Branching ratios to specific products are shown in parentheses. The present study evaluates the extent, represented by the question mark, to which ISOPOO alkyl peroxy radicals might react with $\mathrm{HO}_{2}$ to produce ISOPO alkoxy radicals (Reaction R1b) and thereby MVK and MACR (Reactions R2 and R3).

was the dominant fate of the ISOPOO species, as opposed to the competing $\mathrm{NO}, \mathrm{RO}_{2}$, and isomerization pathways. The concentrations of MVK and MACR were measured using a proton-transfer-reaction time-of-flight mass spectrometer (PTR-TOF-MS) with switchable reagent ion capability $\left(\mathrm{H}_{3} \mathrm{O}^{+}, \mathrm{NO}^{+}\right)$, for which the $\mathrm{NO}^{+}$mode was used to distinguish between MVK and MACR.

\section{Experimental}

The reaction conditions for seven different isoprene photooxidation experiments are listed in Table 1. Experiments \#1 to \#6 correspond to $\mathrm{HO}_{2}$-dominant conditions and Experiment \#7 to NO-dominant conditions. For Experiments \#1 to $\# 6$, the reaction of $\mathrm{H}_{2} \mathrm{O}_{2}$ with $\mathrm{OH}$ radicals was used to produce $\mathrm{HO}_{2}$ radicals: $\mathrm{OH}+\mathrm{H}_{2} \mathrm{O}_{2} \rightarrow \mathrm{HO}_{2}+\mathrm{H}_{2} \mathrm{O}$. For Experiment \#7, a flow of NO into the chamber in the absence of $\mathrm{H}_{2} \mathrm{O}_{2}$ was used, so that the $\mathrm{HO}_{2}$ pathway was not important under these conditions. Experiment \#1 was the main experiment. For Experiments \#2 through \#6, the value of one chamber parameter was halved or doubled relative to Experiment $\# 1$ as an approach to validate experimentally (i) that MVK and MACR were first-generation products (cf. Sect. 3.2) and (ii) that the $\mathrm{HO}_{2}$ pathway was dominant (cf. Sect. 3.3). 
Table 1. Summary of experimental conditions and results.

\begin{tabular}{|c|c|c|c|c|c|c|c|c|}
\hline & \multirow{3}{*}{$\begin{array}{l}\text { Chamber } \\
\text { Condition }^{(1)}\end{array}$} & \multicolumn{5}{|c|}{ Mixing ratio at steady state (ppb) } & \multicolumn{2}{|c|}{ Yield $(\%)(4)$} \\
\hline & & \multicolumn{3}{|c|}{$\mathrm{NO}^{+}$mode } & \multicolumn{2}{|c|}{$\mathrm{H}_{3} \mathrm{O}^{+}$mode } & \multirow[b]{2}{*}{ MVK } & \multirow[b]{2}{*}{ MACR } \\
\hline & & ISOP & MVK & MACR & ISOP & $\begin{array}{l}\text { MVK + } \\
\text { MACR }\end{array}$ & & \\
\hline$\# 1$ & Main experiment $(2)$ & $16.0 \pm 0.6$ & $1.3 \pm 0.1$ & $0.8 \pm 0.1$ & $15.8 \pm 1.4$ & $2.1 \pm 0.2$ & $4.6 \pm 0.7$ & $3.2 \pm 0.6$ \\
\hline$\# 2$ & $0.5 \tau_{\text {ref }}$ & $25.4 \pm 1.1$ & $1.1 \pm 0.1$ & $0.8 \pm 0.1$ & $25.2 \pm 2.2$ & $2.0 \pm 0.2$ & $4.3 \pm 0.7$ & $3.4 \pm 0.6$ \\
\hline \#3 & $2 \tau_{\text {ref }}$ & $9.5 \pm 0.4$ & $1.6 \pm 0.2$ & $0.8 \pm 0.1$ & $9.3 \pm 0.9$ & $2.4 \pm 0.2$ & $6.6 \pm 1.2$ & $4.3 \pm 0.9$ \\
\hline$\# 4$ & $0.5\left[\mathrm{H}_{2} \mathrm{O}_{2}\right]_{\mathrm{in}, \mathrm{ref}}$ & $16.9 \pm 0.7$ & $1.7 \pm 0.2$ & $1.1 \pm 0.2$ & $17.3 \pm 1.4$ & $2.7 \pm 0.3$ & $6.1 \pm 0.9$ & $4.4 \pm 0.8$ \\
\hline \#5 & $2\left[\mathrm{H}_{2} \mathrm{O}_{2}\right]_{\text {in,ref }}$ & $15.8 \pm 0.7$ & $1.3 \pm 0.2$ & $0.7 \pm 0.1$ & $16.2 \pm 1.4$ & $2.0 \pm 0.2$ & $4.5 \pm 0.9$ & $2.8 \pm 0.6$ \\
\hline \#6 & $2[\mathrm{ISOP}]_{\text {in,ref }}$ & $34.5 \pm 1.4$ & $2.1 \pm 0.2$ & $1.6 \pm 0.2$ & $34.1 \pm 3.0$ & $3.6 \pm 0.4$ & $3.7 \pm 0.5$ & $3.2 \pm 0.5$ \\
\hline$\# 7$ & NO-dominant ${ }^{(3)}$ & $18.3 \pm 0.7$ & $10.3 \pm 0.8$ & $7.9 \pm 0.4$ & $18.4 \pm 1.7$ & $18.1 \pm 1.8$ & $41.4 \pm 5.5$ & $29.6 \pm 4.2$ \\
\hline
\end{tabular}

(1) Experiment \#1 is the main experiment. For the other experiments, chamber conditions varied with respect to Experiment \#1 are listed. $[\mathrm{M}]_{\mathrm{in}, \mathrm{ref}}$ represents the inflow mixing ratio of species $\mathrm{M}$ for the the main experiment. $\tau_{\text {ref }}$ is the mean residence time in the chamber for the main experiment. For example, $0.5\left[\mathrm{H}_{2} \mathrm{O}_{2}\right]_{\text {in,ref }}$ in Experiment \#4 indicates that the inflow $\mathrm{H}_{2} \mathrm{O}_{2}$ mixing ratio for Experiment \#4 was half that of the main experiment. Other experimental conditions remain unchanged.

(2) Condition for main experiment: [ISOP $]_{\text {in,ref }}=59 \mathrm{ppb} ;\left[\mathrm{H}_{2} \mathrm{O}_{2}\right]_{\text {in,ref }}=16 \mathrm{ppm}$; no injection of $\mathrm{NO}_{\mathrm{x}}$ and measured NO less than minimum detection limit $(70 \mathrm{ppt})$; $\tau=3.7 \mathrm{~h} ; 25^{\circ} \mathrm{C} ;<2 \%$ relative humidity.

(3) Chamber condition for NO-dominant experiment: no injection of $\mathrm{H}_{2} \mathrm{O}_{2}$; [NO $]_{\text {in }}=28 \mathrm{ppb}$; other conditions same as those of the main experiment

(4) (mean value) $\pm(2 \times$ standard deviation) for mixing ratios and yields. The uncertainties were estimated by Monte Carlo methods.

Experiment \#7 for NO-dominant conditions facilitated comparison of the present study's results to those reported previously in the literature for the yields of MVK and MACR under high- $\mathrm{NO}_{\mathrm{x}}$ conditions.

\subsection{Harvard Environmental Chamber (HEC)}

The experiments were carried out in the Harvard Environmental Chamber (Fig. S1). Detailed descriptions of the chamber were published previously (Shilling et al., 2009; King et al., 2009, 2010). The chamber was operated as a continuously mixed flow reactor (CMFR), with balanced inflows and outflows. A new polyfluoroalkoxy (PFA) Teflon bag with a volume of $5.3 \mathrm{~m}^{3}$ was installed for these experiments. The mean reactor residence time was varied from 1.8 to $7.4 \mathrm{~h}$. Temperature and relative humidity were held at $25 \pm 1{ }^{\circ} \mathrm{C}$ and $<2 \%$, respectively. Ultraviolet irradiation was provided by forty-six Sylvania 350BL blacklights ( $40 \mathrm{~W}$ ) affixed to the walls (King et al., 2009). They had negligible emission for wavelengths below $310 \mathrm{~nm}$.

For the $\mathrm{HO}_{2}$-dominant experiments (\#1 to \#6), isoprene (50 ppm in nitrogen, Scott Specialty Gases), hydrogen peroxide, and dry air (pure air generator, Aadco 737) were continuously injected. Depending on reaction conditions, isoprene concentrations were 59 to $118 \mathrm{ppb}$ in the inflow to the chamber bag and 10 to $35 \mathrm{ppb}$ in the outflow (Table 1). A commercially available ultrapure $\mathrm{H}_{2} \mathrm{O}_{2}$ solution $(31.50 \mathrm{wt} \%$, TraceSELECT ${ }^{@}$ Ultra, Fluka) was used to avoid nitrogencontaining impurities that are present, often as EDTA ligands to stabilize trace metal impurities that enhance the decomposition rate of $\mathrm{H}_{2} \mathrm{O}_{2}$, in typical commercial $\mathrm{H}_{2} \mathrm{O}_{2}$ solutions. In early experiments, the observations showed that nitrogen impurities in the typical $\mathrm{H}_{2} \mathrm{O}_{2}$ solutions ultimately contributed to elevated $\mathrm{NO}_{\mathrm{x}}$ in the bag. Compared to earlier experiments using the $\mathrm{HEC}$ (King et al., 2010), an updated $\mathrm{H}_{2} \mathrm{O}_{2}$ injection system was used to improve stability. $\mathrm{An}_{2} \mathrm{H}_{2}$ solution was continuously introduced by a syringe pump into a warmed glass bulb. The syringe pump was housed in a refrigerator at $4{ }^{\circ} \mathrm{C}$ to avoid $\mathrm{H}_{2} \mathrm{O}_{2}$ decomposition. Dry air at a flow rate of 1-4 sLpm was blown through the bulb to evaporate the injected $\mathrm{H}_{2} \mathrm{O}_{2}$ solution and carry it into the chamber bag. Within the CMFR, photolysis of $\mathrm{H}_{2} \mathrm{O}_{2}$ by ultraviolet light produced $\mathrm{OH}$ radicals, initiating isoprene oxidation. For the NO-dominant experiment (\#7), NO (1.02 ppm NO in nitrogen with $0.01 \mathrm{ppm} \mathrm{NO} \mathrm{N}_{2}$ impurity; Scott Specialty Gases) was injected in place of $\mathrm{H}_{2} \mathrm{O}_{2}$ to produce an inflow concentration of $28.2 \mathrm{ppb} \mathrm{NO}$ and $0.03 \mathrm{ppb} \mathrm{NO} \mathrm{N}_{2}$. Coupled $\mathrm{NO}_{\mathrm{x}}$ and $\mathrm{HO}_{\mathrm{x}}$ photochemical cycles were initiated by photolysis of $\mathrm{NO}_{2}$. The injected NO contributed to increasing the $\mathrm{OH}$ concentration by promoting the conversion of $\mathrm{HO}_{2}$ to $\mathrm{OH}$ according to the reaction: $\mathrm{HO}_{2}+\mathrm{NO} \rightarrow \mathrm{OH}+\mathrm{NO}_{2}$.

The outflow from the HEC was sampled by a PTR-TOFMS, a condensation particle counter (CPC, TSI 3022A), an ozone monitor (Teledyne 400E), and a high-sensitivity $\mathrm{NO}_{\mathrm{x}}$ analyzer (Eco Physics CLD 899 Y). The CPC instrument was used to measure the background number concentration of particles in the HEC, which was below $0.5 \mathrm{~cm}^{-3}$ during the experiments. This low particle number concentration indicated insignificant new particle production. The NO concentration was below the instrument detection limit $(3 \sigma)$ of $70 \mathrm{ppt}$ for Experiments \#1 to \#6. The ozone monitor was used to estimate the $\mathrm{H}_{2} \mathrm{O}_{2}$ concentration in Experiments \#1 to \#6 by using the ratio of the absorption cross-section of $\mathrm{H}_{2} \mathrm{O}_{2}$ to that of $\mathrm{O}_{3}(254 \mathrm{~nm})$ under the assumption that absorption was dominated by $\mathrm{H}_{2} \mathrm{O}_{2}$. The $\mathrm{H}_{2} \mathrm{O}_{2}$ concentration measured by this method was 6.7 to $26 \mathrm{ppm}$ for Experiments \#1 to \#6. 
The expected concentration based on in-flow concentrations but not accounting for physical and reactive losses inside the chamber bag was 8.0 to $32 \mathrm{ppm}$.

\subsection{Mass spectrometry}

A proton-transfer-reaction time-of-flight mass spectrometry (PTR-TOF-MS 8000, Ionicon Analytik GmbH, Austria) equipped with switchable reagent ion capacity was used to measure the concentrations of gaseous organic species in the chamber. For sampling, chamber air was pulled through a PFA sampling line at $1.25 \mathrm{sLpm}$. The PTR-TOF-MS subsampled from this flow at a rate of $0.25 \mathrm{sLpm}$, resulting in a transit time of $4 \mathrm{~s}$ between the chamber and the instrument.

The PTR-TOF-MS was described by Jordan et al. (2009a, b) and Graus et al. (2010). In the present study, either $\mathrm{H}_{3} \mathrm{O}^{+}$ or $\mathrm{NO}^{+}$reagent ions were generated in the ion source and used to selectively ionize organic molecules in the sample air. The use of $\mathrm{NO}^{+}$reagent ions allowed separation of isomeric aldehydes and ketones (Blake et al., 2006), specifically MVK and MACR. The chemical ionization reaction by $\mathrm{NO}^{+}$ or $\mathrm{H}_{3} \mathrm{O}^{+}$is soft, typically resulting in little fragmentation, although relatively weakly bound species still have the possibility for some fragmentation in the drift tube (Smith and Španěl, 2005). The high-resolution TOF detector (Tofwerk AG, Switzerland) was used to analyze the reagent and product ions and allowed for exact identification of the ion molecular formula (mass resolution $>4000$ ).

A calibration system was used to establish the instrument sensitivities to ISOP, MVK, and MACR. Gas standards (5.12 ppm ISOP and 5.26 ppm MVK in $\mathrm{N}_{2}$, and $5.27 \mathrm{ppm}$ MACR in $\mathrm{N}_{2}$; Scott Specialty Gases) were added into the sample flow at controlled flow rates. In each experiment, the inlet flow was switched to dry air from the pure air generator to establish background intensities.

Settings of the drift tube were optimized to measure MVK and MACR at high sensitivity. The instrument was operated with a drift tube temperature of $60^{\circ} \mathrm{C}$ and a drift tube pressure of $2.2 \mathrm{mbar}$. In $\mathrm{H}_{3} \mathrm{O}^{+}$mode, the drift tube voltage was set to $520 \mathrm{~V}$, resulting in an $E / N=118 \mathrm{Td}$ ( $E$, electric field strength; $N$, number density of air in the drift tube; unit, Townsend, Td; $1 \mathrm{Td}=10^{-17} \mathrm{~V} \mathrm{~cm}^{2}$ ). In $\mathrm{NO}^{+}$ mode, a drift tube voltage of $300 \mathrm{~V}$ was used, resulting in an $E / N=68 \mathrm{Td}$. At this reduced $E / N$ ratio, ionization of MVK and MACR led to distinct product ions while retaining a highly sensitive instrument response.

PTR-TOF-MS spectra were collected at a time resolution of $1 \mathrm{~min}$. A custom data processing package was developed in Mathematica (ver 8.0, Wolfram Research, USA) to analyze the recorded mass spectra. Using this package, the relative mass deviation was less than $10 \mathrm{ppm}$ over the spectrum. The package consisted of several sub-routines: peak shape fitting, mass calibration, peak assignment, and signal analysis (cf. Supplement). Compared with the analysis method reported in Müller et al. (2010), the main difference was in fitting of the asymmetric peak shape. Müller et al. approximated the peak shape using the superposition of four Gaussian peaks, but this method did not work well for the peaks of the present study, possibly because of different instrument tuning. Instead, several strong single-ion peaks (e.g., the peak for $\mathrm{H}_{3}^{18} \mathrm{O}^{+}$ion for $\mathrm{H}_{3} \mathrm{O}^{+}$mode) were used to produce an empirically derived reference peak shape, which was then used globally in the peak fitting routine.

\subsection{Low-temperature trap}

The reactions of ISOPOO with $\mathrm{HO}_{2}$ can produce $\mathrm{C}_{5}$ products that have multiple functional groups, including organic hydroperoxides ISOPOOH and its further oxidation products dihydroxyl epoxides (IEPOX; cf. Fig. S2) (Paulot et al., 2009). These products possibly fragment after collision with $\mathrm{H}_{3} \mathrm{O}^{+}$or $\mathrm{NO}^{+}$in the PTR-TOF-MS (Smith and Španěl, 2005), and the resultant fragment ions may have the same $m / z$ values as the product ions of MVK and MACR because they all inherit the carbon skeleton from isoprene. As an approach to separate possible ISOPOOH and IEPOX products from MVK and MACR, prior to injection into the PTRTOF-MS the outflow from the HEC was passed through a $1 \mathrm{~m}$ PFA coil (inner diameter $3 / 16 \mathrm{inch}=4.76 \mathrm{~mm}$ ) that was immersed in a low temperature liquid bath. As the temperature of the bath was decreased in discrete steps from +25 to $-40^{\circ} \mathrm{C}$, molecules of progressively lower vapor pressures sequentially condensed in the coil and were thereby removed from the gas flow. This approach is particularly suited to separating low-volatility compounds such as ISOPOOH and IEPOX from high-volatility species like MVK and MACR. The quantification of MVK and MACR was based on PTRTOF-MS measurements downstream of the trap at $-40^{\circ} \mathrm{C}$ (cf. Sects. 3.1 and 3.6 for further discussion).

\subsection{Modeling with MCM v3.2}

The contribution by different reaction pathways was estimated for each experiment using a kinetic box model (Chen et al., 2011). The kinetic scheme for isoprene chemistry was extracted from the MCM v3.2 via website: http://mcm. leeds.ac.uk/MCM (Jenkin et al., 1997; Saunders et al., 2003). Model runs were initialized using the conditions of each experiment (Table 1), with the exception of the $\mathrm{H}_{2} \mathrm{O}_{2}$ concentration. Instead of using the $\mathrm{H}_{2} \mathrm{O}_{2}$ injection rates as shown in Table 1 , the spectroscopically measured steady-state $\mathrm{H}_{2} \mathrm{O}_{2}$ concentrations of each experiment were used as a constraint in the model. The one-sun photolysis rates of the MCM model were scaled by 0.3 to match the lower light intensity of the HEC. 


\section{Results and discussion}

The results and discussion section is organized as follows. Section 3.1 presents the separation of MVK and MACR using the $\mathrm{NO}^{+}$reagent ion and the quantification of the concentrations of ISOP, MVK, and MACR. Section 3.2 explains how the yields of MVK and MACR $\left(Y_{\mathrm{MVK}}\right.$ and $\left.Y_{\mathrm{MACR}}\right)$ were obtained from the concentration measurements. The quantitative uncertainties of $Y_{\mathrm{MVK}}$ and $Y_{\mathrm{MACR}}$ were also established. Section 3.3 presents the qualitative evidence that these yields were recorded under conditions of $\mathrm{HO}_{2}$-dominant reactions for the ISOPOO species (Reactions R1, R2, and R3). Section 3.4 explains how to constrain the minor contribution of the NO pathway to $Y_{\mathrm{MVK}}$ and $Y_{\mathrm{MACR}}$ using the yields measured under varying experimental conditions, yielding a best estimate for the yields of MVK and MACR via the $\mathrm{HO}_{2}$ pathway $\left(Y_{\mathrm{MVK}, \mathrm{HO}_{2}}\right.$ and $\left.Y_{\mathrm{MACR}, \mathrm{HO}_{2}}\right)$. Section 3.5 provides a comparison of the results of the present study to those reported previously in the literature. Section 3.6 presents evidence of chemical interferences for MVK and MACR that without precaution can confound the analytic method (cf. Sect. 3.1) and that these species are organic hydroperoxides.

\subsection{Quantification of ISOP, MVK, and MACR}

The $\mathrm{NO}^{+}$mass spectra recorded for zero air, ISOP, MVK, and MACR standards are shown in Fig. 2. The dominant product ion of the reaction of ISOP $\left(\mathrm{C}_{5} \mathrm{H}_{8}\right)$ with $\mathrm{NO}^{+}$was the charge-transfer ion $\mathrm{C}_{5} \mathrm{H}_{8}{ }^{+}(\mathrm{m} / \mathrm{z}, 68.0621)$, in agreement with $\mathrm{Karl}$ et al. (2012). $\mathrm{NO}^{+}$reacted with the aldehyde MACR $\left(\mathrm{C}_{4} \mathrm{H}_{6} \mathrm{O}\right)$ to yield mainly the dehydride ion $\mathrm{C}_{4} \mathrm{H}_{5} \mathrm{O}^{+}$ $(m / z \quad 69.0335)$ and a small amount of the $\mathrm{C}_{4} \mathrm{H}_{6} \mathrm{O}^{\cdot} \mathrm{NO}^{+}$ cluster ion $\left(m / z\right.$ 100.0393). $\mathrm{NO}^{+}$reacted with the ketone MVK $\left(\mathrm{C}_{4} \mathrm{H}_{6} \mathrm{O}\right)$ to produce mainly the $\mathrm{C}_{4} \mathrm{H}_{6} \mathrm{O}^{\cdot} \mathrm{NO}^{+}$cluster ion. Ion-molecule clustering reactions are favorable when no other exothermic channel is available, as is especially the case for the reaction of $\mathrm{NO}^{+}$with ketones (Španěl et al., 1997). The hydride ion $\left(\mathrm{H}^{-}\right)$transfer reaction is favorable for aldehydes because extraction of the $\mathrm{H}^{-}$ion from a - $\mathrm{CHO}$ moiety requires less energy than from a hydrocarbon chain. These ionization patterns have been observed for ketones and aldehydes using $\mathrm{NO}^{+}$in selective-ion flow-tube studies $(E / N=0 \mathrm{Td})$ (Španěl et al., 2002). In comparison, the proton transfer reaction of MVK and MACR with $\mathrm{H}_{3} \mathrm{O}^{+}$ gave rise dominantly to $\mathrm{C}_{4} \mathrm{H}_{7} \mathrm{O}^{+}(m / z$ 71.0492).

In an iterative process, the $E / N$ value was optimized to isolate the product ions of MACR from those of MVK while retaining high instrument sensitivity (cf. Fig. S3). Compared with an earlier drift tube study using $\mathrm{NO}^{+}$(Blake et al., 2006), less fragmentation was observed in the present study, both for MVK and MACR, possibly because of the lower drift tube energies used here (i.e., $E / N=68 \mathrm{Td}$ compared to $E / N=165 \mathrm{Td}$ ). The good separation achieved with $\mathrm{NO}^{+}$enabled separate quantification of MVK and MACR in

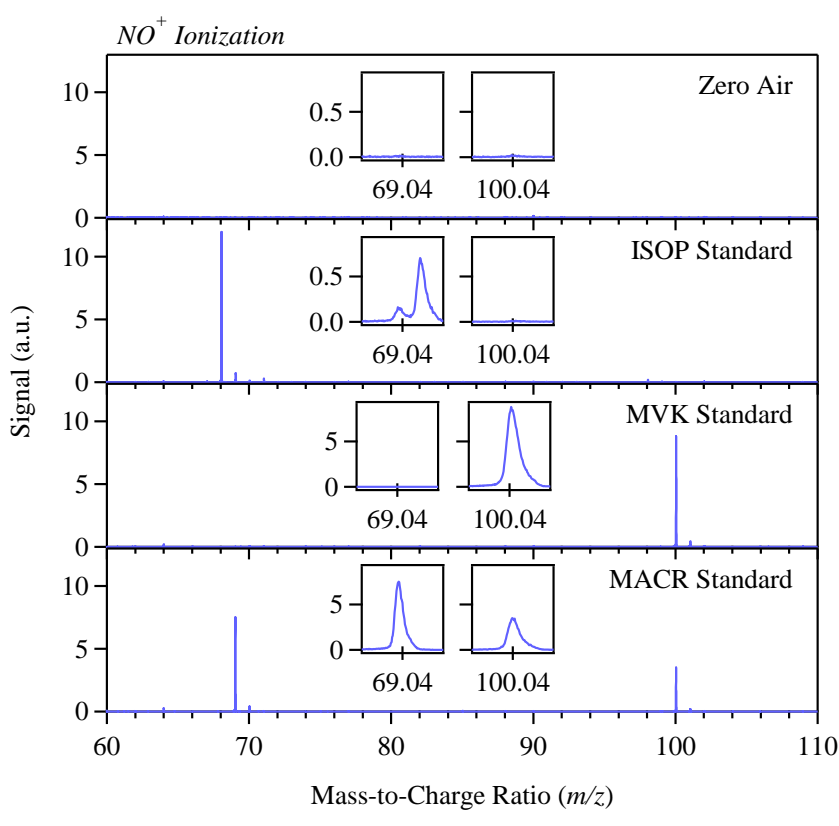

Fig. 2. Mass spectra of zero air, ISOP, MVK, and MACR measured using PTR-TOF-MS with $\mathrm{NO}^{+}$reagent ion. Insets show expansions near $m / z 69$ and $m / z \quad 100$, corresponding at $m / z$ 69.0335 to $\mathrm{C}_{4} \mathrm{H}_{5} \mathrm{O}^{+}$contributed by MACR and ISOP, at $m / z$ 69.0654 to $\mathrm{C}_{4}{ }^{13} \mathrm{CH}_{8}+$ contributed by ISOP, and at $m / z 100.0393$ to $\mathrm{C}_{4} \mathrm{H}_{6} \mathrm{O}^{\cdot} \mathrm{NO}^{+}$contributed by MVK and MACR.

the mixed composition present in the chamber outflow. The small contribution of MACR to the $\mathrm{C}_{4} \mathrm{H}_{6} \mathrm{O}^{\cdot} \mathrm{NO}^{+}$cluster ion was corrected for algebraically (cf. Eqs. S1-S3).

The sensitivities of the PTR-TOF-MS to ISOP, MVK, and MACR determined for trap temperatures of +25 and $-40^{\circ} \mathrm{C}$ are listed in Table 2. To account for possible matrix effects, calibrations for both $\mathrm{H}_{3} \mathrm{O}^{+}$and $\mathrm{NO}^{+}$were carried out for each experiment by standard addition to the outflow air from the chamber (i.e., prior to the low-temperature trap). For both the $\mathrm{H}_{3} \mathrm{O}^{+}$and $\mathrm{NO}^{+}$modes, the sensitivities did not depend on trap temperature. This temperature independence indicates that ISOP, MVK, and MACR did not condense at a trap temperature of $-40^{\circ} \mathrm{C}$. Hence, MVK and MACR were effectively separated from other oxidation products of lower volatility by use of the trap at $-40^{\circ} \mathrm{C}$ (cf. Sect. 3.6). The ISOP, MVK, and MACR concentrations reported herein were based on $\mathrm{NO}^{+}$ionization and using the $-40^{\circ} \mathrm{C}$ trap prior to the PTR-TOF-MS.

As a comparison point, the sensitivity of isoprene in $\mathrm{NO}^{+}$ mode measured in this study agreed with the value reported by Karl et al. (2012) for similar $E / N$ ratios (cf. Supplement). With respect to the $\mathrm{H}_{3} \mathrm{O}^{+}$mode, the sensitivities of ISOP, MVK, and MACR differed from the theoretically expected values by less than $10 \%$ (Zhao and Zhang, 2004; de Gouw and Warneke, 2007). The signal for $\mathrm{C}_{3} \mathrm{H}_{5}{ }^{+}(\mathrm{m} / z$ 41.039), an isoprene fragment in $\mathrm{H}_{3} \mathrm{O}^{+}$mode, was $6 \%$ of the main isoprene signal and lay within the range of $3 \%$ to $16 \%$ reported 
Table 2. Sensitivities of the PTR-TOF-MS to ISOP, MVK, and MACR.

\begin{tabular}{|c|c|c|c|c|c|c|c|}
\hline \multirow{3}{*}{ Species } & \multirow{3}{*}{$\begin{array}{l}\text { Chemical } \\
\text { Formula }\end{array}$} & \multicolumn{3}{|c|}{$\mathrm{NO}^{+}$mode } & \multicolumn{3}{|c|}{$\mathrm{H}_{3} \mathrm{O}^{+}$mode } \\
\hline & & \multirow[t]{2}{*}{$\begin{array}{l}\text { Product } \\
\text { ions }\end{array}$} & \multicolumn{2}{|c|}{$\begin{array}{c}\text { Sensitivity } \\
\left(\text { ncps ppb }^{-1}\right)^{(1)}\end{array}$} & \multirow[t]{2}{*}{$\begin{array}{l}\text { Product } \\
\text { ions }\end{array}$} & \multicolumn{2}{|c|}{$\begin{array}{c}\text { Sensitivity } \\
\left(\mathrm{ncps} \mathrm{ppb}^{-1}\right)\end{array}$} \\
\hline & & & $+25^{\circ} \mathrm{C}^{(2)}$ & $-40^{\circ} \mathrm{C}^{(2)}$ & & $+25^{\circ} \mathrm{C}$ & $-40^{\circ} \mathrm{C}$ \\
\hline ISOP & $\mathrm{C}_{5} \mathrm{H}_{8}$ & $\mathrm{C}_{5} \mathrm{H}_{8}{ }^{+}$ & $15.7 \pm 0.4^{(3)}$ & $15.9 \pm 0.6$ & $\mathrm{C}_{5} \mathrm{H}_{9}{ }^{+}$ & $16.8 \pm 1.4$ & $16.2 \pm 1.1$ \\
\hline MVK & $\mathrm{C}_{4} \mathrm{H}_{6} \mathrm{O}$ & $\mathrm{C}_{4} \mathrm{H}_{6} \mathrm{O} \cdot \mathrm{NO}^{+}$ & $23.1 \pm 1.8$ & $23.7 \pm 1.2$ & $\mathrm{C}_{4} \mathrm{H}_{7} \mathrm{O}^{+}$ & $30.6 \pm 2.9$ & $29.2 \pm 1.5$ \\
\hline \multirow[t]{2}{*}{ MACR } & $\mathrm{C}_{4} \mathrm{H}_{6} \mathrm{O}$ & $\mathrm{C}_{4} \mathrm{H}_{5} \mathrm{O}^{+}$ & $15.0 \pm 0.8$ & $15.0 \pm 0.4$ & $\mathrm{C}_{4} \mathrm{H}_{7} \mathrm{O}^{+}$ & $30.0 \pm 2.8$ & $28.7 \pm 2.2$ \\
\hline & & $\mathrm{C}_{4} \mathrm{H}_{6} \mathrm{O} \cdot \mathrm{NO}^{+}$ & $8.8 \pm 0.8$ & $8.9 \pm 0.5$ & & & \\
\hline
\end{tabular}

(1) The unit ncps is the measured counts per second (cps) normalized to a primary ion signal of $10^{6} \mathrm{cps}$.

(2) Sensitivities were determined for trap temperatures of +25 and $-40^{\circ} \mathrm{C}$.

(3) Measurements are represented as (mean value) $\pm(2 \times$ standard deviation) based on sensitivities determined across Experiments \#1 through \#7.

in the literature (e.g., Ammann et al., 2004; McKinney et al., 2011).

Table 1 presents the steady-state concentrations of ISOP, MVK, and MACR measured in $\mathrm{NO}^{+}$mode as well as the steady-state concentrations of ISOP and MVK + MACR measured in $\mathrm{H}_{3} \mathrm{O}^{+}$mode determined from the data at $-40^{\circ} \mathrm{C}$. The combined concentration of MVK and MACR measured using $\mathrm{H}_{3} \mathrm{O}^{+}$ionization agreed with the sum of the speciated measurements using $\mathrm{NO}^{+}$ionization for all experiments.

\subsection{Yields of MVK and MACR: $Y_{M V K}$ and $Y_{M A C R}$}

The yield of MVK (MACR) is equal to the sum of the mathematical product of (i) the branching ratio leading to the precursor ISOPBOO (ISOPDOO) in the initial reaction of isoprene with $\mathrm{OH}$ and (ii) the branching ratios to the channels forming ISOPBO (ISOPDO) in the subsequent ISOPBOO (ISOPDOO) reactions (cf. Fig. 1). The reactant and product concentrations in the CMFR at steady state can be incorporated in an analysis to determine MVK (MACR) product yields. The relationship of mass balance for the sources and sinks of MVK (MACR) is given by the following equation:

$$
\begin{aligned}
0 & =\left(Y_{\mathrm{MVK}} k_{\mathrm{ISOP}+\mathrm{OH}}[\mathrm{OH}]_{\mathrm{ss}}[\mathrm{ISOP}]_{\mathrm{ss}}\right)_{\text {sources }} \\
& -\left(k_{\mathrm{MVK}+\mathrm{OH}}[\mathrm{OH}]_{\mathrm{ss}}[\mathrm{MVK}]_{\mathrm{ss}}+\frac{1}{\tau}[\mathrm{MVK}]_{\mathrm{ss}}\right. \\
& \left.+k_{\mathrm{wall}}[\mathrm{MVK}]_{\mathrm{ss}}\right)_{\mathrm{sinks}}
\end{aligned}
$$

in which $[\mathrm{M}]_{\mathrm{ss}}$ is the steady-state chamber concentration of compound M, $Y_{\mathrm{MVK}}$ is the yield of MVK from isoprene oxidation for one set of chamber conditions, $\tau$ is the mean residence time in the chamber, $k_{\mathrm{ISOP}+\mathrm{OH}}$ and $k_{\mathrm{MVK}+\mathrm{OH}}$ are the reaction rate constants of ISOP and $\mathrm{MVK}$ with $\mathrm{OH}$, and $k_{\text {wall }}$ is the steady-state wall loss rate coefficient of MVK. Control experiments show that a photolysis sink for MVK (MACR) was negligible, at least for the conditions of the conducted experiments. Rearrangement of Eq. (1) leads to the expres- sion for the yield of MVK, as follows:

$Y_{\mathrm{MVK}}=\frac{\left(k_{\mathrm{MVK}+\mathrm{OH}}[\mathrm{OH}]_{\mathrm{ss}}+1 / \tau+k_{\mathrm{wall}}\right)[\mathrm{MVK}]_{\mathrm{ss}}}{k_{\mathrm{ISOP}+\mathrm{OH}}[\mathrm{OH}]_{\mathrm{ss}}[\mathrm{ISOP}]_{\mathrm{ss}}}$

For $Y_{\mathrm{MACR}}$, a direct analogy to Eq. (2) exists.

For use of Eq. (2), values of $k_{\mathrm{ISOP}+\mathrm{OH}}$ and $k_{\mathrm{MVK}+\mathrm{OH}}$, including their uncertainties, were taken from the IUPAC database (Atkinson et al., 2006). A value of $k_{\text {wall }}=0 \mathrm{~s}^{-1}$ was used based on the results of wall-loss experiments for ISOP, MVK, and MACR that were performed separately in the HEC (cf. Supplement). The value of $[\mathrm{OH}]_{\mathrm{ss}}$ was calculated based on measurements of the isoprene concentration prior to the reaction (i.e., dark conditions) and at steady state (i.e., during photo-oxidation), as follows:

$$
\begin{aligned}
0 & =\left(\frac{1}{\tau}[\mathrm{ISOP}]_{\text {in }}\right)_{\text {sources }} \\
& -\left(k_{\mathrm{ISOP}+\mathrm{OH}}[\mathrm{OH}]_{\mathrm{ss}}[\mathrm{ISOP}]_{\mathrm{ss}}+\frac{1}{\tau}[\mathrm{ISOP}]_{\mathrm{ss}}\right)_{\text {sinks }}
\end{aligned}
$$

in which [ISOP $]_{\text {in }}$ was the inflow concentration of isoprene to the HEC. The steady-state $\mathrm{OH}$ concentration inferred by use of Eq. (3) varied from 1.8 to $2.0 \times 10^{6} \mathrm{~cm}^{-3}$ for Experiments \#1 to \#6.

Yields of MVK and MACR for each experiment are listed in Table 1. In the case of Experiment \#1, the MVK and MACR yields by Eq. (2) and its analog were (4.6 \pm 0.7$) \%$ and $(3.2 \pm 0.6) \%$, respectively, for reaction at $25^{\circ} \mathrm{C}$ and $<2 \% \mathrm{RH}$. The uncertainties $(2 \sigma)$ for $Y_{\mathrm{MVK}}$ and $Y_{\mathrm{MACR}}$ were estimated using a Monte Carlo method in which the values of all input parameters in Eqs. (2) and (3) were sampled from probability density functions of their individual values (i.e., their individual uncertainties). An example of the input and output uncertainties is presented in Table S1. The uncertainties in the concentrations were based on calibrations. The uncertainties in the reaction rate coefficients were obtained from the IUPAC recommendations. A $6 \% 2 \sigma$-uncertainty was used for the chamber residence time based on the standard deviation in measured residence times for multiple experiments. The ensembles of results for $Y_{\mathrm{MVK}}$ and $Y_{\mathrm{MACR}}$, 
which can be approximated by normal distributions (Fig. S4), were the basis of the reported statistical errors to the mean values.

In the case of Experiment \#7 for NO-dominant conditions, MVK and MACR were produced in high yields as a result of the reaction of ISOPOO with NO (e.g., Tuazon and Atkinson, 1990). Ozone produced as part of the $\mathrm{NO}_{\mathrm{x}}$ photochemical cycle also reacted to a small extent with ISOP, MVK, and MACR in this experiment. Equations (1)-(3) were therefore expanded to include this chemistry, with rate constants taken from the IUPAC database (cf. Eqs. S4-S6). The ozone concentration $(65 \mathrm{ppb})$ measured in the chamber outflow was used, resulting in a calculated $\mathrm{OH}$ concentration of $1.5 \times 10^{6} \mathrm{~cm}^{-3}$ with ozone correction. For these concentrations, $90 \%$ of isoprene reacted with $\mathrm{OH}$ and $10 \%$ with $\mathrm{O}_{3}$. The ozonolysis of isoprene also provided an additional source term for MVK and MACR. This term, with MVK and MACR yields taken from Aschmann and Atkinson (1994), was also included in the calculation (cf. Eqs. S4S6). The resulting MVK and MACR yields (Table 1) were $(36.8 \pm 4.4) \%$ and $(31.8 \pm 3.9) \%$ without ozone correction and $(41.4 \pm 5.5) \%$ and $(29.6 \pm 4.2) \%$ with the correction.

The source term in Eq. (1) is written assuming that MVK is not produced through any process other than as a firstgeneration product of $\mathrm{OH}$ reaction with isoprene. Secondary oxidation processes of some isoprene oxidation products, like ISOPOOH $\left(\mathrm{C}_{5} \mathrm{H}_{10} \mathrm{O}_{3}\right)$ and IEPOX $\left(\mathrm{C}_{5} \mathrm{H}_{10} \mathrm{O}_{3}\right)$, could conceivably also produce some MVK and MACR and therefore represent an additional source term. For example, the MCM suggests that photolysis of ISOPOOH can lead to ISOPO and hence MVK and MACR, although the modeled contribution of ISOPOOH photolysis is $<1 \%$ of the combined production rate of MVK and MACR in Experiment \#1. As one test of the data against the possibility of additional production by secondary sources (photolysis and otherwise), experiments were conducted for halved $(\# 2 ; 1.9 \mathrm{~h})$ and doubled $(\# 3 ; 7.4 \mathrm{~h}$ ) chamber residence times relative to Experiment \#1. As expected, for an increase (decrease) in chamber residence time, the steady-state concentration of isoprene decreased (increased) while those of its oxidation products increased (decreased). The MVK and MACR yields were expected to remain constant only in the absence of significant secondary production. That is, significant secondary production would lead to non-linearity in the yields with respect to residence time. For halving the residence time (Experiment \#2, Table 1; Fig. 3a), however, these changes in concentration left the yield unchanged compared to Experiment \#1. Doubling the residence time (Experiment \#3, Table 1; Fig. 3a) did increase the MVK and MACR yields. Therefore, secondary processes seemed to produce significant quantities of MVK and MACR only for $\tau \gg 3.7 \mathrm{~h}$, and shorter residence times such as in Experiment \#1 produced yields representative of first-generation products.
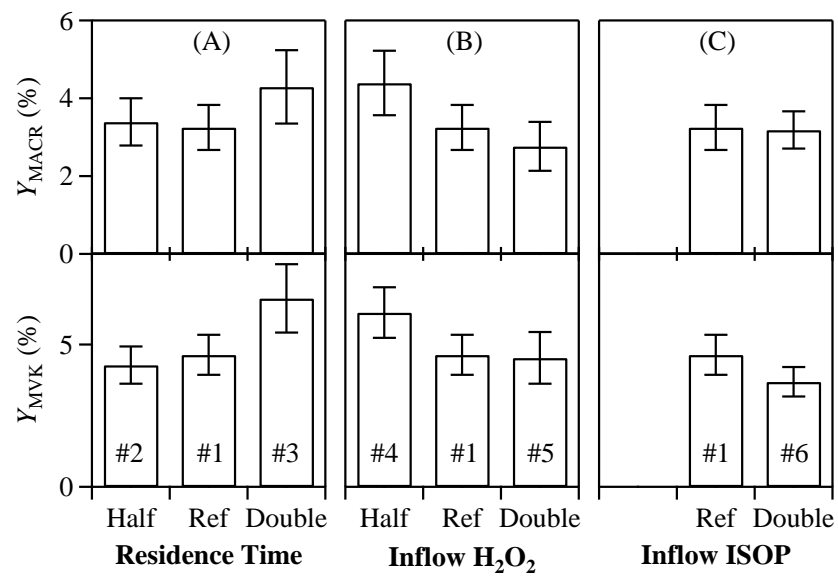

Fig. 3. Yields of MACR (top) and $\mathrm{MVK}$ (bottom) for $\mathrm{HO}_{2}-$ dominant conditions. (A) Variable residence time. (B) Variable inflow concentration of $\mathrm{H}_{2} \mathrm{O}_{2}$. (C) Variable inflow concentration of ISOP. The labeled experiment numbers refer to Table 1 .

\subsection{Verification of $\mathrm{HO}_{2}$-dominant fate for ISOPOO radicals}

The dominant regime for the fate of the ISOPOO radicals, whether that of $\mathrm{HO}_{2}, \mathrm{NO}, \mathrm{RO}_{2}$, or isomerization reactions, was assessed both computationally with the assistance of MCM simulations and experimentally by empirical observation of the effects of varying the reaction conditions on the results. The $\mathrm{HO}_{2}$ and $\sum \mathrm{RO}_{2}$ concentrations modeled by the $\mathrm{MCM}$, in conjunction with the upper limit of NO concentration based on measurement, were used to calculate the contribution of each pathway to the fate of ISOPOO in each experiment. The results are presented in Table 3. For Experiment $\# 1$, the modeled concentrations of $\mathrm{HO}_{2}$ and $\sum \mathrm{RO}_{2}$ were 540 ppt and 17 ppt, respectively, and the measured NO was below the detection limit (70 ppt), resulting in a calculated contribution of $>93 \%$ from the $\mathrm{HO}_{2}$ pathway, $<6 \%$ from the $\mathrm{NO}$ pathway, and $1 \%$ for the $\mathrm{RO}_{2}$ and isomerization pathways. The calculated contribution from the $\mathrm{HO}_{2}$ pathway represents a lower limit because as a stringency test the calculation used an upper limit for the NO concentration (70 ppt). Actual NO concentration was likely lower because of titration by $\mathrm{HO}_{2}$, perhaps on order of $3 \mathrm{ppt}$ based on the MCM model simulation or $14 \mathrm{ppt}$ based on inversion analysis (cf. Sect. 3.4).

The titration of $\mathrm{NO}$ by $\mathrm{HO}_{2}$ was verified experimentally. A flow of $0.5 \mathrm{ppb} \mathrm{NO}$ was introduced with the chamber inflow for the same experimental conditions as Experiment \#1. No change was observed in the NO signal (below detection limit) or the PTR signals for major product ions (Fig. S5). The $\mathrm{NO}_{\mathrm{x}}$ concentration increased as expected, implying that $\mathrm{NO}$ was titrated by excess $\mathrm{HO}_{2}$ to produce $\mathrm{NO}_{2}$. This observation is consistent with the MCM simulations, which suggest a steady-state $\mathrm{NO}$ concentration of $6 \mathrm{ppt}$ in the presence of an 
Table 3. Modeled relative importance of competing reaction pathways for Experiments \#1 to \#7.

\begin{tabular}{|c|c|c|c|c|c|c|c|c|c|c|c|}
\hline & \multicolumn{3}{|c|}{$\begin{array}{l}\text { Mixing ratios } \\
\quad(\mathrm{ppt})\end{array}$} & \multicolumn{4}{|c|}{$\begin{array}{c}\text { Reaction rates with } \\
\text { ISOPOO }\left(10^{-2} \mathrm{~s}^{-1}\right)^{(3)}\end{array}$} & \multicolumn{4}{|c|}{$\begin{array}{c}\text { Contribution by } \\
\text { pathway }(\%)\end{array}$} \\
\hline & $\mathrm{NO}^{(1)}$ & $\mathrm{HO}_{2}^{(2)}$ & $\sum \mathrm{RO}_{2}^{(2)}$ & NO & $\mathrm{HO}_{2}$ & $\mathrm{RO}_{2}$ & ISOM & NO & $\mathrm{HO}_{2}$ & $\mathrm{RO}_{2}$ & ISOM \\
\hline \#1 & $<70$ & 541 & 17 & 1.5 & 23 & 0.1 & 0.2 & $<6$ & 93 & 0.3 & 0.8 \\
\hline$\# 2$ & $<70$ & 532 & 23 & 1.5 & 23 & 0.1 & 0.2 & $<6$ & 93 & 0.4 & 0.8 \\
\hline \#3 & $<70$ & 540 & 13 & 1.5 & 23 & 0.1 & 0.2 & $<6$ & 93 & 0.2 & 0.8 \\
\hline \#4 & $<70$ & 354 & 25 & 1.5 & 15 & 0.1 & 0.2 & $<9$ & 89 & 0.7 & 1.2 \\
\hline \#5 & $<70$ & 795 & 12 & 1.5 & 34 & 0.1 & 0.2 & $<4$ & 95 & 0.1 & 0.6 \\
\hline \#6 & $<70$ & 500 & 35 & 1.5 & 21 & 0.2 & 0.2 & $<7$ & 92 & 0.7 & 0.9 \\
\hline \#7 & 910 & 28 & 25 & 20 & 1.2 & 0.1 & 0.2 & 93 & 6 & 0.5 & 0.9 \\
\hline
\end{tabular}

\footnotetext{
(1) Value measured by $\mathrm{NO}_{\mathrm{x}}$ analyzer, which had a detection limit of $70 \mathrm{ppt}$.

(2) Value simulated using MCM v3.2 for the employed reaction conditions.

(3) Reaction rate coefficients of ISOPOO used here: $8.8 \times 10^{-12} \mathrm{~cm}^{3} \mathrm{molec}^{-1} \mathrm{~s}^{-1}$ for NO and $1.74 \times 10^{-11} \mathrm{~cm}^{3} \mathrm{molec}^{-1} \mathrm{~s}^{-1}$ for $\mathrm{HO}_{2}$ (Atkinson et al., 2006). A single effective reaction rate coefficient with value of $1.8 \times 10^{-12} \mathrm{~cm}^{3} \mathrm{molec}^{-1} \mathrm{~s}^{-1}$ was used for the $\mathrm{RO}_{2}$ family. This value represents the average reaction rate coefficient of the ISOROO isomers weighted by their respective branching ratios in MCM v3.2. The isomerization rate coefficient measured experimentally $\left(0.002 \mathrm{~s}^{-1}\right)$ by Crounse et al. (2011) was used. A higher contribution of isomerization pathway ( $4 \%$ for Experiment \#1) was expected using the rate coefficient predicted by Peeters and Muller $\left(0.01 \mathrm{~s}^{-1}\right)(2010)$.
}

inflow NO concentration of $0.5 \mathrm{ppb}$. Another line of evidence is that the nitrate-containing ion observed in the high- $\mathrm{NO}_{\mathrm{x}}$ experiment (Experiment \#7), which was the protonated ion of peroxyacetyl nitrate $\left(\mathrm{C}_{2} \mathrm{H}_{4} \mathrm{NO}_{5}{ }^{+}\right)$(Hansel and Wisthaler, 2000), was absent in all other experiments (Fig. S6).

The accuracy of the foregoing modeling analysis, represented by Table 3, is subject to the uncertainties of the kinetic scheme of MCM v3.2 as well as pathways not included in the scheme, such as possible unaccounted-for wall loss rates or photolysis rates of reactive intermediates, principally ISOPOO. Experiments \#4 to \#6 were designed to supplement the modeling analysis by providing empirical verification that there was no significant contribution to Experiment \#1 from pathways other than $\mathrm{HO}_{2}$.

Experiments \#4 and \#5 employed halved and doubled $\mathrm{H}_{2} \mathrm{O}_{2}$ inflow concentrations, respectively, thereby changing the steady-state concentration of $\mathrm{HO}_{2}$ (cf. Table 3). As represented in the MCM (v3.2), the yields of MVK and MACR are $41.5 \%$ and $26.5 \%$ via the NO pathway and $35.5 \%$ and $24.5 \%$ via the $\mathrm{RO}_{2}$ pathway, and the respective yields are predicted as $16 \%$ and $9 \%$ via the isomerization pathway (Peeters and Muller, 2010). The observed yields in the $\mathrm{HO}_{2}$ dominant experiments in the present study were much lower than expected yields from any of the other pathways. Hence, in the case that other pathways significantly competed with $\mathrm{HO}_{2}$, the MVK and MACR yields would have increased (decreased) with a decrease (increase) of the $\mathrm{H}_{2} \mathrm{O}_{2}$ and hence $\mathrm{HO}_{2}$ concentrations. As shown in Fig. 3b, doubling the $\mathrm{H}_{2} \mathrm{O}_{2}$ concentration (Experiment \#5, Table 1) did not decrease the yield compared with Experiment \#1, implying that pathways other than the $\mathrm{HO}_{2}$ channel were not important for Experiments \#1 and \#5. These other channels did start to have an influence when the $\mathrm{H}_{2} \mathrm{O}_{2}$ concentration was halved, which increased the MVK and MACR yields (Experiment \#4, Table 1).

Experiment \#6 was designed as a further empirical test of the importance of the $\mathrm{RO}_{2}$ pathway relative to the $\mathrm{HO}_{2}$ pathway. Doubling the isoprene inflow concentration in Experiment \#6 increased the steady-state concentration of $\mathrm{RO}_{2}$ (cf. Table 3), yet the MVK and MACR yields did not increase (Fig. 3c), supporting the conclusion that the $\mathrm{RO}_{2}$ pathway was not significant in Experiment \#1.

Two other possible reaction pathways of ISOPOO include wall collisions (i.e., leading to possible depositional loss or heterogeneous reaction) and photolysis. McMurry and Grosjean (1985) provided a formulation to estimate the lifetime of gas-phase species in a chamber against wall collisions. For the experimental conditions of the present study, the estimate was on order $10^{3} \mathrm{~s}$. By comparison, the lifetime of ISOPOO against $\mathrm{HO}_{2}$ was $5 \mathrm{~s}$ for the conditions of Experiment \#1, suggesting that wall collisions were at most of minor importance for the fate of ISOPOO.

Although the absorption spectrum of ISOPOO radicals is not known specifically, oxygen-substituted organic peroxy radicals typically absorb across the range 200 to $300 \mathrm{~nm}$ (Lightfoot et al., 1992; Wallington et al., 1992). By comparison, the employed lamps had negligible photo emission for wavelengths shorter than $310 \mathrm{~nm}$. The data analysis therefore omits a photolysis channel. Even so, a caveat is that there is at least one case, represented by the $\mathrm{CH}_{3} \mathrm{C}(\mathrm{O}) \mathrm{CH}_{2} \mathrm{OO}$ radical, for which absorption above $300 \mathrm{~nm}$ was reported (Cox et al., 1990).

The results of the high- $\mathrm{NO}_{\mathrm{x}}$ experiment (\#7) also provide evidence that wall collisions and photolysis were unimportant for the fate of ISOPOO. The yields $Y_{\mathrm{MVK}, \mathrm{NO}}$ and $Y_{\mathrm{MACR}, \mathrm{NO}}$ agreed with those reported in the literature for a wide range of reaction conditions (cf. Sect. 3.5). This 
agreement suggests an absence in Experiment \#7 of significant ISOPOO wall collisions or photolysis. The lifetime of ISOPOO against NO $(0.9 \mathrm{ppb})$ was $5 \mathrm{~s}$ for Experiment \#7. Because the lifetime of ISOPOO against $\mathrm{HO}_{2}$ for Experiment \#1 was also $5 \mathrm{~s}$, the logical inference is that wall collisions and photolysis were also unimportant fates of ISOPOO in that experiment.

\subsection{Best estimate for $\boldsymbol{Y}_{\mathrm{MVK}, \mathrm{HO}_{2}}$ and $\boldsymbol{Y}_{\mathrm{MACR}, \mathrm{HO}_{2}}$}

The MCM simulations and empirical experiments both support qualitatively that there was a dominant contribution of $\mathrm{HO}_{2}$ pathway to the fate of ISOPOO for Experiment \#1 (Sect. 3.3). The present section provides a quantitative assessment of the possible effects of minor contributions from other pathways and the best estimate for $Y_{\mathrm{MVK}_{2} \mathrm{HO}_{2}}$ and $Y_{\mathrm{MACR}, \mathrm{HO}_{2}}$. The focus of the analysis is on the competing NO pathway, established in Sect. 3.3 as the most significant pathway competing with $\mathrm{HO}_{2}$ for the conditions of the experiments.

The possible minor contribution of the NO pathway to the yields of MVK and MACR in the $\mathrm{HO}_{2}$-dominant experiments was estimated by constructing a kinetic model having branching ratios $\xi_{\mathrm{HO}_{2}}$ and $\xi_{\mathrm{NO}}$ for the fate of ISOPOO with $\mathrm{HO}_{2}$ and $\mathrm{NO}$, respectively, and then applying a fit of the model to the observed yields from the three experiments using various $\mathrm{H}_{2} \mathrm{O}_{2}$ concentrations. The model is constructed as follows. In the case that MVK was produced only by $\mathrm{HO}_{2}$ and $\mathrm{NO}$ reactions, $Y_{\mathrm{MVK}}=Y_{\mathrm{MVK}, \mathrm{HO}_{2}} \xi_{\mathrm{HO}_{2}}+Y_{\mathrm{MVK}, \mathrm{NO}} \xi_{\mathrm{NO}}$. For the case of ISOPOO loss only by these reactions, the branching ratios can be expanded, and the observed yield $Y_{\mathrm{MVK}}$ of MVK is then as follows:

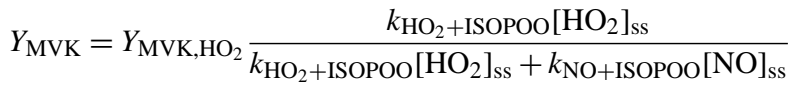

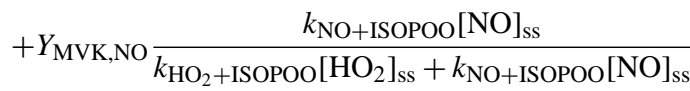

An analogous equation exists for $Y_{\mathrm{MACR}}$. Terms in Eq. (4) include the yields $Y_{\mathrm{MVK}, \mathrm{NO}}$ and $Y_{\mathrm{MVK}, \mathrm{HO}_{2}}$ of MVK for the $\mathrm{NO}$ and $\mathrm{HO}_{2}$ pathways, the reaction rates coefficients

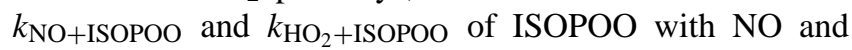
$\mathrm{HO}_{2}$, and the steady-state concentrations $[\mathrm{NO}]_{\mathrm{ss}}$ and $\left[\mathrm{HO}_{2}\right]_{\mathrm{ss}}$ of $\mathrm{NO}$ and $\mathrm{HO}_{2}$.

Any NO contamination in the chamber was taken to have a zero-order source term $k_{0, \mathrm{NO}}$ independent of reactions conditions. For instance, there can be NO present in the inflow air (i.e., what passes through the pure air generator), or NO can diffuse from the outside chamber environment through the walls of the Teflon bag into the reaction zone. Because NO was produced slowly but reacted quickly with the excess $\mathrm{HO}_{2}$, we invoke the steady-state approximation and write:

$0=k_{0, \mathrm{NO}}-k_{\mathrm{NO}+\mathrm{HO}_{2}}[\mathrm{NO}]_{\mathrm{ss}}\left[\mathrm{HO}_{2}\right]_{\mathrm{ss}}$

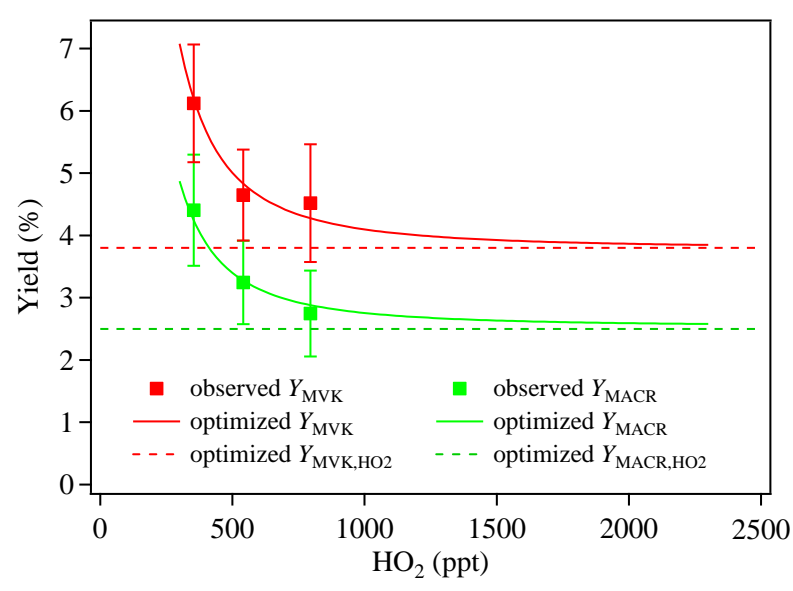

Fig. 4. Optimization of $Y_{\mathrm{MVK}, \mathrm{HO}_{2}}$ and $Y_{\mathrm{MACR}, \mathrm{HO}_{2}}$ using the yield data of MVK and MACR according to Eq. (6).

where $k_{\mathrm{NO}+\mathrm{HO}_{2}}$ is the reaction rate coefficient of $\mathrm{NO}$ and $\mathrm{HO}_{2}$. Combining Eqs. (4) and (5), we have:

$$
\begin{aligned}
Y_{\mathrm{MVK}} & =Y_{\mathrm{MVK}, \mathrm{HO}_{2}}\left(1+\frac{k^{\prime}}{\left[\mathrm{HO}_{2}\right]_{\mathrm{Ss}}^{2}}\right)^{-1} \\
& +Y_{\mathrm{MVK}, \mathrm{NO}}\left(1+\frac{\left[\mathrm{HO}_{2}\right]_{\mathrm{SS}}^{2}}{k^{\prime}}\right)^{-1}
\end{aligned}
$$

where $k^{\prime}=\frac{k_{\mathrm{NO}+\mathrm{ISOPOO}} k_{0, \mathrm{NO}}}{k_{\mathrm{HO}_{2}+\mathrm{ISOPOO}} k_{\mathrm{NO}+\mathrm{HO}_{2}}}$. There is an analogous equation (not shown) to Eq. (6) for $Y_{\mathrm{MACR}}$.

Regarding Eq. (6), known terms include $Y_{\mathrm{MVK}, \mathrm{NO}}$ as determined in the high- $\mathrm{NO}_{\mathrm{x}}$ experiment (\#7), $Y_{\mathrm{MVK}}$ that was measured, and $\left[\mathrm{HO}_{2}\right]_{\mathrm{ss}}$ that was simulated by the MCM (Table 3). Unknown terms are $Y_{\mathrm{MVK}, \mathrm{HO}_{2}}$ and $k^{\prime}$. Experiments $\# 1$, \#4, and \#5 represent three realizations of Eq. (6). Similarly, there are three realizations for $Y_{\mathrm{MACR}, \mathrm{HO}_{2}}$ and $k^{\prime}$. Overall, there are therefore six statements of equality and three terms $Y_{\mathrm{MVK}, \mathrm{HO}_{2}}, Y_{\mathrm{MACR}, \mathrm{HO}_{2}}$, and $k^{\prime}$. These terms were numerically optimized by the Levenberg-Marquardt algorithm so as to minimize the sum-of-the-square of differences of the equality statements of the six realizations. Uncertainty estimates $(2 \sigma)$ in $Y_{\mathrm{MVK}, \mathrm{HO}_{2}}, Y_{\mathrm{MACR}, \mathrm{HO}_{2}}$, and $k^{\prime}$ were obtained by a Monte Carlo method of sampling from the uncertainties in the input parameters and reevaluating the values of the optimized parameters (Fig. S7). An uncertainty of $30 \%$ was used for the simulated $\mathrm{HO}_{2}$ concentrations based on the uncertainties in the reaction rate constants of the dominant source and sink of $\mathrm{HO}_{2}$.

The fits after numerical optimization are shown in Fig. 4 for Eq. (6) compared to the data. Optimized values are as follows: $Y_{\mathrm{MVK}, \mathrm{HO}_{2}}=(3.8 \pm 1.3) \%$ and $Y_{\mathrm{MACR}, \mathrm{HO}_{2}}=(2.5 \pm$ $0.9) \%$. The steady-state NO concentrations, corresponding to the obtained $k^{\prime}$ value $\left(7.5_{-4.9}^{+14.1} 10^{3} \mathrm{ppt}^{2}\right)$, were $21_{-13}^{+31}$, $14_{-9}^{+26}$, and $9_{-6}^{+21} \mathrm{ppt}$ for the conditions of half, reference, and double $\mathrm{H}_{2} \mathrm{O}_{2}$, respectively. For these results, Eq. (6) implies 

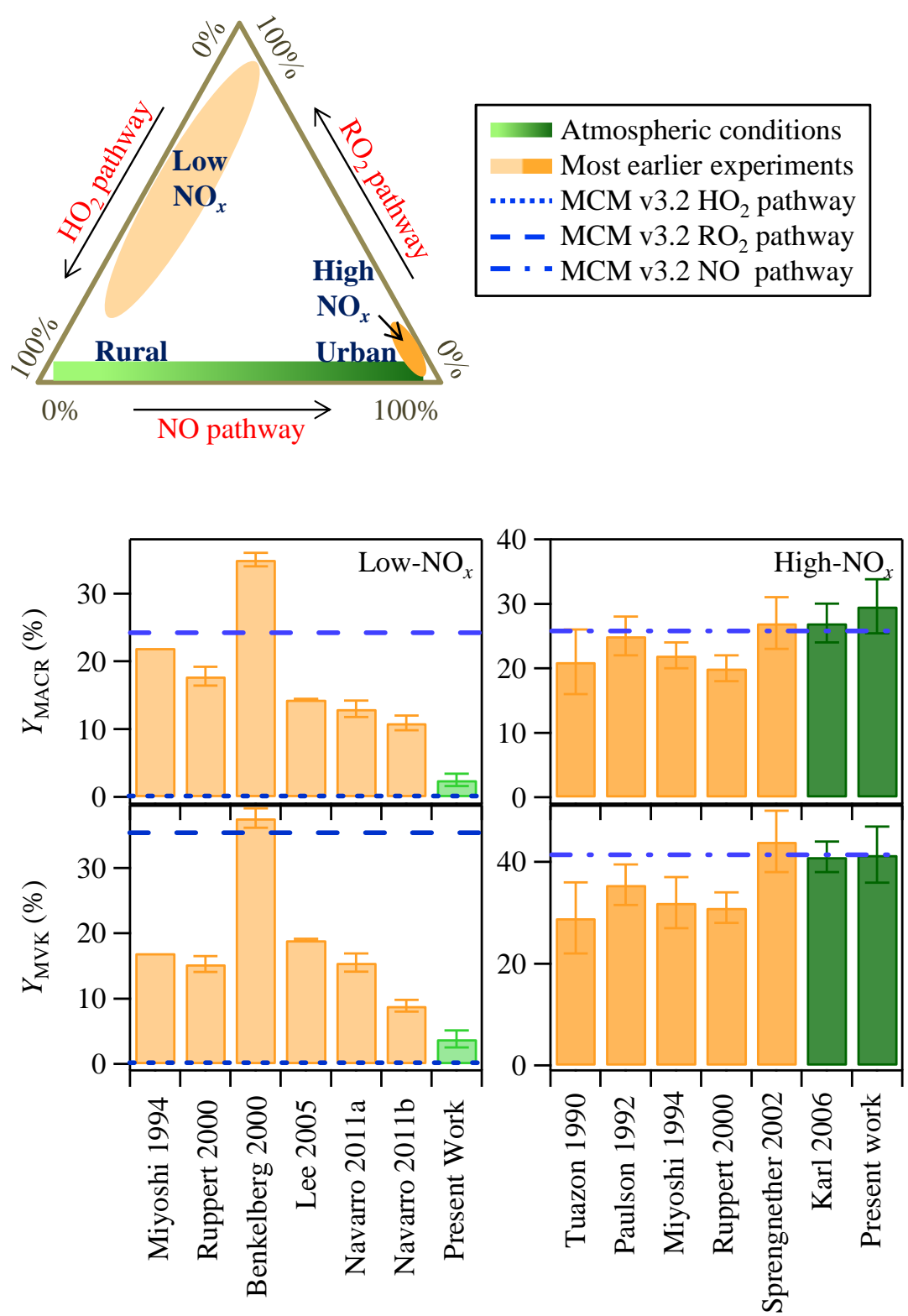

Fig. 5. Comparison of the MVK and MACR yields from ISOP photo-oxidation in this study with those in earlier studies for conditions described in those studies as "low $\mathrm{NO}_{\mathrm{x}}$ " and "high $\mathrm{NO}_{\mathrm{x}}$ " (bar) and with those of $\mathrm{RO}_{2}, \mathrm{HO}_{2}$, or $\mathrm{NO}$ pathways represented in $\mathrm{MCM}$ (line). The inset triangle diagram represents environmental factors that can affect the dominant reaction pathways of isoprene-derived ISOPOO radicals in the atmosphere and in the laboratory studies. The isomerization pathway is not included due to its small contribution in most laboratory studies, although it could be important in remote atmospheric conditions. Cited studies: Tuazon and Atkinson (1990), Miyoshi et al. (1994), Paulson et al. (1992), Benkelberg et al. (2000), Ruppert and Becker (2000), Sprengnether et al. (2002), Lee et al. (2005), Karl et al. (2006), and Navarro et al. (2011). The modeled ratio of $\mathrm{HO}_{2}$ to $\mathrm{RO}_{2}$ is 0.1 and 1 in Navarro (2011) Exp a and Exp b, respectively.

that the branching ratios of ISOPOO to the $\mathrm{HO}_{2}$ and $\mathrm{NO}$ pathways are 0.97 and 0.03, respectively, for Experiment \#1.

\subsection{Comparison with the literature}

Laboratory studies investigating isoprene oxidation chemistry generally have been categorized as either "high- $\mathrm{NO}_{\mathrm{x}}$ " or "low-NO ${ }_{\mathrm{x}}$ " experiments (Tuazon and Atkinson, 1990; Paul- son et al., 1992; Miyoshi et al., 1994; Ruppert and Becker, 2000; Benkelberg et al., 2000; Sprengnether et al., 2002; Lee et al., 2005; Karl et al., 2006; Paulot et al., 2009; Navarro et al., 2011; Crounse et al., 2011). Figure 5 shows a comparison of the yields of MACR and MVK via the $\mathrm{HO}_{2}$ and NO pathway quantified in this study to the yields reported in earlier "low- $\mathrm{NO}_{\mathrm{x}}$ " and "high- $\mathrm{NO}_{\mathrm{x}}$ " experimental studies and also the yields represented in the MCM. The yields of MVK and 
MACR via the NO pathway quantified in the NO-dominant experiments are in good agreement with the yields reported in earlier "high- $\mathrm{NO}_{\mathrm{x}}$ " experiments and also the yields used in the MCM for the NO pathway.

The yields of MVK and MACR reported herein for the $\mathrm{HO}_{2}$ pathway are 60-90\% lower than the yields reported in other "low-NO $\mathrm{NO}_{\mathrm{x}}$ " experiments (Miyoshi et al., 1994; Ruppert and Becker, 2000; Benkelberg et al., 2000; Lee et al., 2005; Navarro et al., 2011). Several factors may contribute to this difference. For all of the cited literature studies, the $\mathrm{RO}_{2}$ pathway was expected to have a significant or even dominant contribution to the ISOPOO chemistry because initial isoprene concentrations of 1 to $100 \mathrm{ppm}$ were used, compared to the $<0.1 \mathrm{ppm}$ concentrations of the present study. Miyoshi et al. (1994) found that the yields of MVK and MACR increased for higher isoprene: $\mathrm{H}_{2} \mathrm{O}_{2}$ ratios, an experimental parameter which regulated the ratio of $\mathrm{RO}_{2}$ to $\mathrm{HO}_{2}$. Navarro et al. (2011) observed that the yields of MVK and MACR dropped as the ratio of $\mathrm{HO}_{2}$ to $\mathrm{RO}_{2}$ increased from 0.1 to 1. Higher yields of MVK and MACR are expected from the $\mathrm{RO}_{2}$ pathway than from the $\mathrm{HO}_{2}$ pathway according to currently accepted mechanisms, including the MCM (Fig. 5). Hence, these findings suggest that both the $\mathrm{RO}_{2}$ and the $\mathrm{HO}_{2}$ channels contributed to the observed MVK and MACR production in these "low- $\mathrm{NO}_{\mathrm{x}}$ " experiments. Another issue for some "low- $\mathrm{NO}_{\mathrm{x}}$ " studies is that the background NO concentration was typically not well measured, e.g., $<100 \mathrm{ppb}$ of $\mathrm{NO}_{\mathrm{x}}$ reported in the study by Ruppert and Becker (2000). $\mathrm{NO}_{\mathrm{x}}$ and HONO off-gassing have been observed in many chamber systems (Carter et al., 2005; Rohrer et al., 2005). Injection of $\mathrm{H}_{2} \mathrm{O}_{2}$ could also increase the measured $\mathrm{NO}_{\mathrm{x}}$ level in the reactor depending on the concentration of nitrogen impurities in the $\mathrm{H}_{2} \mathrm{O}_{2}$ solution, as found in the present study. An unaccounted contribution from the background $\mathrm{NO}$ in the earlier "low- $\mathrm{NO}_{\mathrm{x}}$ " experiments, therefore, could be another reason for the higher reported yields. The present study achieved low NO concentrations (verified experimentally to be below the detection limit of $70 \mathrm{ppt}$ and inverse modeled as 10 to $20 \mathrm{ppt}$ ) by use of a high-purity $\mathrm{H}_{2} \mathrm{O}_{2}$ solution, of a chamber bag never exposed to high concentrations of $\mathrm{NO}_{\mathrm{x}}$, and operation in a CMFR configuration.

Paulot et al. (2009) probed the $\mathrm{HO}_{2}$ pathway using ppblevel isoprene concentrations and negative chemical ionization mass spectrometry (CIMS). A combined yield of MVK and MACR was reported because the CIMS instrument did not separately measure isomeric MVK and MACR. This yield was $(12 \pm 12) \%$ via the $\mathrm{HO}_{2}$ pathway, with the large uncertainty dependent on an initial amount of $\mathrm{NO}_{\mathrm{x}}$ in the chamber (Paulot et al., 2009). The result of the present study, $(6.3 \pm 2.1) \%$ for the combined yield of MVK and MACR, is consistent with the yield range of that study.

\subsection{Organic hydroperoxides and epoxides}

Changes in the signal intensities of $\mathrm{C}_{5} \mathrm{H}_{8}{ }^{+}, \mathrm{C}_{4} \mathrm{H}_{5} \mathrm{O}^{+}$, and $\mathrm{C}_{4} \mathrm{H}_{6} \mathrm{NO}_{2}{ }^{+}$ions produced using the $\mathrm{NO}^{+}$reagent ion are shown in Fig. 6 for stepwise decreases in trap temperature from +25 to $-40^{\circ} \mathrm{C}$. Results are shown for Experiments $\# 1$ and \#7, representing $\mathrm{HO}_{2}$-dominant and NO-dominant conditions, respectively. The ion intensities plotted in Fig. 6 nominally represent ISOP, MACR, and MVK: the data show that in the $\mathrm{HO}_{2}$-dominant experiments additional species contributed to these ions for trap temperatures warmer than $-30^{\circ} \mathrm{C}$. The more general formula $\mathrm{C}_{4} \mathrm{H}_{6} \mathrm{NO}_{2}{ }^{+}$is therefore used in place of $\mathrm{C}_{4} \mathrm{H}_{6} \mathrm{O}^{*} \mathrm{NO}^{+}$because specific formulas of the additional species are not known.

The signal intensity for the $\mathrm{C}_{5} \mathrm{H}_{8}{ }^{+}$ion did not depend on trap temperature for either dominant oxidation pathway. The implication is that there was no chemical interference for isoprene detection via the $\mathrm{C}_{5} \mathrm{H}_{8}{ }^{+}$ion. Likewise, the signal intensities of the $\mathrm{C}_{4} \mathrm{H}_{5} \mathrm{O}^{+}$and $\mathrm{C}_{4} \mathrm{H}_{6} \mathrm{NO}_{2}{ }^{+}$ions did not depend on temperature for the NO-dominant experiments, implying that these ions represented the instrument response to MACR and MVK in those experiments. By comparison, the signal intensities of the nominal $\mathrm{C}_{4} \mathrm{H}_{5} \mathrm{O}^{+}$and $\mathrm{C}_{4} \mathrm{H}_{6} \mathrm{NO}_{2}{ }^{+}$ions depended strongly on temperature from 0 to $-30^{\circ} \mathrm{C}$ in the $\mathrm{HO}_{2}$-dominant experiments, implying the presence of other molecular products that were removed at low temperature. The signal intensities were independent of temperature from -30 to $-40^{\circ} \mathrm{C}$, meaning that the interference products were fully removed from the gas phase at the trap temperature below $-30^{\circ} \mathrm{C}$ and hence the $\mathrm{C}_{4} \mathrm{H}_{5} \mathrm{O}^{+}$and $\mathrm{C}_{4} \mathrm{H}_{6} \mathrm{NO}_{2}{ }^{+}$ions at $-40^{\circ} \mathrm{C}$ represented the instrument response to MACR and MVK. Temperature-dependent patterns of signal intensity using the $\mathrm{H}_{3} \mathrm{O}^{+}$reagent ions (Fig. S8) were similar to the results shown in Fig. 6 for the $\mathrm{NO}^{+}$reagent ions.

For the $\mathrm{HO}_{2}$-dominant experiments, the signal intensities of the $\mathrm{C}_{4} \mathrm{H}_{5} \mathrm{O}^{+}$and $\mathrm{C}_{4} \mathrm{H}_{6} \mathrm{NO}_{2}{ }^{+}$ions were stable at temperatures warmer than $0^{\circ} \mathrm{C}$. As the trap temperature cooled below $0^{\circ} \mathrm{C}$, the signal intensities first decreased and then returned to the original level. This dip-recovery behavior suggests adsorption on the cold inner walls of the trap coil followed by thermodynamic equilibration between partial and vapor pressures with time. As the trap temperature decreased further, the dip in signal intensity increased and the rate of recovery decreased, consistent with a longer approach to equilibrium for decreased vapor pressures at lower temperatures. For $-30^{\circ} \mathrm{C}$, recovery was no longer observed, suggesting that the surface uptake process transitioned from adsorption to condensation.

With high plausibility, the condensing species can be inferred to be a mixture of organic hydroperoxides (ISOPOOH) and possibly epoxides (IEPOX) based on their physical properties and the dominant chemical pathways. There are two lines of evidence. (1) The condensing species were absent for the NO-dominant experiments, implying that the condensing products were produced exclusively by the 


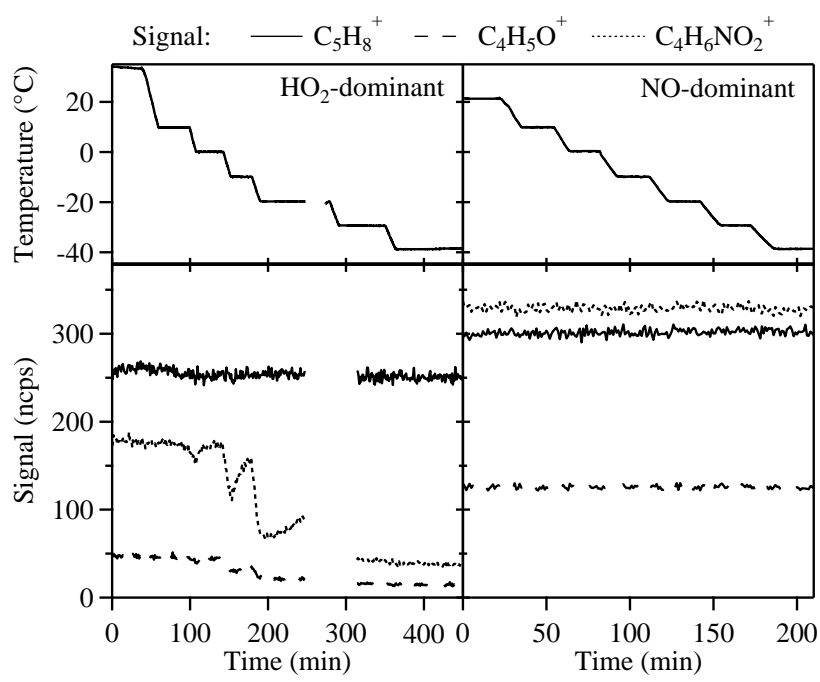

Fig. 6. Time series of (top) trap temperature and (bottom) signal intensities of $\mathrm{C}_{5} \mathrm{H}_{8}{ }^{+}(\mathrm{m} / \mathrm{z}, 69.0654), \mathrm{C}_{4} \mathrm{H}_{5} \mathrm{O}^{+}(\mathrm{m} / \mathrm{z}$ 69.0335), and $\mathrm{C}_{4} \mathrm{H}_{6} \mathrm{NO}_{2}{ }^{+}$ions $(\mathrm{m} / z$ 100.0393). These ions nominally represent ISOP, MACR, and MVK, respectively, when using the $\mathrm{NO}^{+}$reagent ion (cf. Fig. S8 for $\mathrm{H}_{3} \mathrm{O}^{+}$). Results are shown both for $\mathrm{HO}_{2}$ - and NO-dominant conditions (Experiments \#1 and \#7).

$\mathrm{HO}_{2}$ pathway. ISOPOOH $\left(\mathrm{C}_{5} \mathrm{H}_{10} \mathrm{O}_{3}\right)$ and IEPOX $\left(\mathrm{C}_{5} \mathrm{H}_{10} \mathrm{O}_{3}\right)$ are oxidation products formed exclusively by the $\mathrm{HO}_{2}$ pathway. Paulot et al. (2009) reported a yield of $>70 \%$ for ISOPOOH from the reaction of $\mathrm{HO}_{2}+$ ISOPOO and a yield of $>75 \%$ for IEPOX from further oxidation of ISOPOOH by $\mathrm{OH}$. (2) The condensing species had lower volatilities than MVK and MACR because neither MVK nor MACR condensed at $-40{ }^{\circ} \mathrm{C}$ (Table 2). Compared with MVK and MACR, the ISOPOOH and IEPOX species have multiple functional groups as well as an additional carbon atom. Correspondingly, their vapor pressures are lower than MVK and MACR (Pankow and Asher, 2008).

The expected PTR-MS product ions of ISOPOOH and IEPOX assuming no fragmentation were not observed in the chamber air using either $\mathrm{H}_{3} \mathrm{O}^{+}$or $\mathrm{NO}^{+}$reagent ions. Therefore, either thermal decomposition in the instrument $\left(60^{\circ} \mathrm{C}\right)$ or fragmentation following ionization occurred to these two compounds in both modes. A set of experiments was carried out to investigate how the operating parameters of the PTR-TOF-MS might influence the fragmentation or the decomposition of the species that had condensed in the lowtemperature trap. The results are included in the Supplement. The conclusion of the analysis is that ionization processes are the better explanation than thermal decomposition.

To further assess whether ISOPOOH and IEPOX can fragment to ions at the same $m / z$ ratio as the product ions of MVK and MACR, the fragmentation patterns for proxy compounds or authentic standards were tested. $\beta$-IEPOX (cf. Fig. S2), which is the most abundant IEPOX isomer produced from isoprene (Paulot et al., 2009), was synthesized following the procedure of Zhang et al. (2012). The ionization of $\beta$-IEPOX mainly led to $\mathrm{C}_{5} \mathrm{H}_{7} \mathrm{O}^{+}$ions in $\mathrm{H}_{3} \mathrm{O}^{+}$mode and $\mathrm{C}_{5} \mathrm{H}_{6} \mathrm{O}^{+}$ions in $\mathrm{NO}^{+}$mode, which are different from the product ions of MVK and MACR. Under the assumption of similar fragmentation patterns for all the isomers of IEPOX, the conclusion is that IEPOX was not the condensing species that contributed to the same $m / z$ ratio as the MVK and MACR ions.

Because no ISOPOOH standards were available, tertbutyl hydroperoxide $\left(\mathrm{M}=\mathrm{C}_{4} \mathrm{H}_{10} \mathrm{O}_{3}\right)$ was instead tested as a proxy compound. The main product ions included $(\mathrm{M}-(\mathrm{OOH}))^{+}$, (MH- $\left.(\mathrm{OH})-\left(\mathrm{CH}_{3}\right)\right)^{+}$, and $\left(\mathrm{MH}-\left(\mathrm{H}_{2} \mathrm{O}\right)\right)^{+}$in the $\mathrm{H}_{3} \mathrm{O}^{+}$mode. For the $\mathrm{NO}^{+}$mode, $(\mathrm{M}-(\mathrm{OOH}))^{+}$and $\left(\mathrm{M} \cdot \mathrm{NO}-(\mathrm{OH})-\left(\mathrm{CH}_{3}\right)\right)^{+}$were observed. As presented in Reaction (R4), the production of (M*NO- $\left.(\mathrm{OH})-\left(\mathrm{CH}_{3}\right)\right)^{+}$in the $\mathrm{NO}^{+}$mode might be due to a loss of a $\beta$-carbon and an $-\mathrm{OH}$ from the - $\mathrm{OOH}$ group to produce a carbonyl compound upon reaction with $\mathrm{NO}^{+}$. A similar pathway can produce $(\mathrm{MH}-$ $\left.(\mathrm{OH})-\left(\mathrm{CH}_{3}\right)\right)^{+}$in $\mathrm{H}_{3} \mathrm{O}^{+}$mode. Under the supposition that similar chemical processes can occur for $\mathrm{M}=\mathrm{ISOPOOH}$, the product ions are identical to those produced by MVK and MACR in the PTR-TOF-MS analysis (Reactions R5 and R6). A further line of evidence in favor of hydroperoxides is the variation of signal intensities with chamber residence time (cf. Fig. S9). The equivalent concentrations of the interference for MVK and MACR (defined as the difference in the concentrations of MVK and MACR quantified at the trap temperature of $25^{\circ} \mathrm{C}$ and those at $-40^{\circ} \mathrm{C}$ ) were higher for shorter residence times, suggesting that the contributing compounds are first-generation products, i.e., hydroperoxides rather than epoxides.<smiles>CC(C)(C)OO</smiles>

tert- $\mathrm{C}_{4} \mathrm{H}_{9} \mathrm{OOH}$<smiles>C=CC(C)(CO)CO</smiles>

ISOPBOOH<smiles>C=C(C)C(CO)OO</smiles>

ISOPDOOH

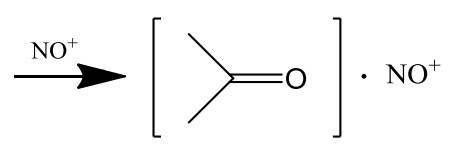

$\mathrm{C}_{3} \mathrm{H}_{6} \mathrm{O} \cdot \mathrm{NO}^{+}$

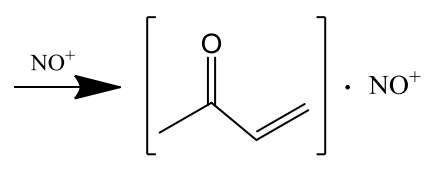

$\mathrm{C}_{4} \mathrm{H}_{6} \mathrm{O} \cdot \mathrm{NO}^{+}$<smiles>C=C(C)C=O</smiles>

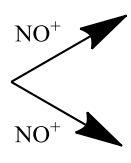

$\mathrm{C}_{4} \mathrm{H}_{6} \mathrm{O} \cdot \mathrm{NO}^{+}$

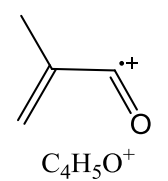




\section{Conclusions and atmospheric implications}

Photo-oxidation experiments of isoprene were conducted in a steady-state chamber for $\mathrm{HO}_{2}$-dominant and $\mathrm{NO}$-dominant conditions. The concentrations of ISOP, MVK, and MACR in the chamber were measured with a PTR-TOF-MS equipped with switchable $\mathrm{H}_{3} \mathrm{O}^{+}$and $\mathrm{NO}^{+}$reagent ion capacities. The use of $\mathrm{NO}^{+}$allowed separate quantification of isomeric MVK and MACR, which was not possible using $\mathrm{H}_{3} \mathrm{O}^{+}$ alone. For both the $\mathrm{H}_{3} \mathrm{O}^{+}$and $\mathrm{NO}^{+}$modes, some other oxidation products produced under the $\mathrm{HO}_{2}$-dominant conditions fragmented to ions having the same $\mathrm{m} / \mathrm{z}$ ratios as the product ions of MVK and MACR.

These results have implications for the use of PTR-MS instruments to elucidate isoprene chemistry in clean atmospheric environments, which are typically characterized by high $\mathrm{HO}_{2}$ : NO concentration ratios (i.e., favoring the $\mathrm{HO}_{2}$ dominant pathway) (Fig. 5). The $\mathrm{C}_{4} \mathrm{H}_{7} \mathrm{O}^{+}$ions in $\mathrm{H}_{3} \mathrm{O}^{+}$ mode have been exclusively attributed to MVK and MACR (de Gouw and Warneke, 2007; Blake et al., 2009). The results of the present study, showing interference compounds for the $\mathrm{HO}_{2}$-dominant conditions, indicate that analytical errors may occur. The interference compounds, plausibly attributable to organic hydroperoxides, have low volatility and were removed by adding a low-temperature trap $\left(-40^{\circ} \mathrm{C}\right)$ in the sampling line prior to the PTR-TOF-MS.

With respect to the yields of MVK and MACR, a steadystate approach was used in this study's analysis (Eq. 2). This approach was validated by the good agreement between the yields measured under high- $\mathrm{NO}_{\mathrm{x}}$ conditions and those reported in the literature. For the low- $\mathrm{NO}_{\mathrm{x}}$ conditions of the present study, both kinetic modeling and inferential experimental evidence were consistent with the $\mathrm{HO}_{2}$ pathway as the dominant fate of ISOPOO. Small contributions from other pathways to the measured MVK and MACR yields were assessed using experimental data, resulting in a yield for MVK of $(3.8 \pm 1.3) \%$ and a yield for MACR of $(2.5 \pm 0.9) \%$ for isoprene photo-oxidation via the $\mathrm{HO}_{2}$ pathway for the present study.

These reported yields for the $\mathrm{HO}_{2}$ pathway are 60 to $90 \%$ smaller than most other "low- $\mathrm{NO}_{\mathrm{x}}$ " experiments. This difference is mainly attributed to significant contributions from the $\mathrm{RO}_{2}$ pathway associated with the high isoprene concentrations (1-100 ppm) used in other studies (cf. Fig. 5). In real atmospheric conditions, the $\mathrm{RO}_{2}$ pathway is less important because of low atmospheric VOC concentrations, typically $10 \mathrm{ppt}$ to $10 \mathrm{ppb}$ (cf. Fig. 5). Caution is therefore needed when directly applying the results from laboratory "low- $\mathrm{NO}_{\mathrm{x}}$ " experiments to atmospheric "low- $\mathrm{NO}_{\mathrm{x}}$ " conditions. Instead, it is recommended that the dominant reaction pathway, such as $\mathrm{HO}_{2}$-dominant or NO-dominant, be specified in place of the more ambiguous descriptors of "low$\mathrm{NO}_{\mathrm{x}}$ " and "high- $\mathrm{NO}_{\mathrm{x}}$ " conditions.

The production of MVK and MACR from ISOPOO through the $\mathrm{HO}_{2}$ reaction pathway is concomitant with $\mathrm{OH}$ production, according to Reaction (R1b). Therefore, the MVK and MACR yields via the $\mathrm{HO}_{2}$ pathway imply a concomitant yield of hydroxyl radical from Reaction (R1b) of $(6.3 \pm 2.1) \%$. The total $\mathrm{OH}$ yield from Reaction (R1b) could be higher because only recycling of ISOPBOO and ISOPDOO are evaluated here. This value is consistent with the study of Taraborrelli et al. (2012) which constrained the $\mathrm{OH}$ yield from Reaction (R1b) to $<15 \%$. Reactions (R2) and (R3), which are subsequent to Reaction (R1b), produce $\mathrm{HO}_{2}$ at a yield of $(6.3 \pm 2.1) \%$ of the ISOPOO and $\mathrm{HO}_{2}$ initially reacted. Therefore, the $\mathrm{HO}_{\mathrm{x}}$ recycling by the channel investigated in the present study is $(12.6 \pm 4.2) \%$, given that $\mathrm{OH}$ and $\mathrm{HO}_{2}$ are both reactant and products.

A growing body of observational evidence suggests significant discrepancies in modeled and measured $\mathrm{OH}$ concentrations in atmospheric environments having high isoprene emissions and high $\mathrm{HO}_{2}$ : NO ratios (e.g., Lelieveld et al., 2008; Stone et al., 2011). An OH-recycling channel for the reaction of ISOPOO and $\mathrm{HO}_{2}$ (Reaction $\mathrm{R} 1 \mathrm{~b}$ ) was proposed to explain the discrepancy. Recycling of 200-300\% $\mathrm{OH}$ radicals (i.e., amplification) was needed to close the gap between model predictions and atmospheric measurements over the coastal Amazon rainforest (Lelieveld et al., 2008; Butler et al., 2008) as well as in a Southeast Asian rainforest (Stone et al., 2011). Therefore, the present study's result of $(12.6 \pm 4.2) \%$ recycling of $\mathrm{HO}_{\mathrm{x}}$ is insufficient to close the gap. Not all possible $\mathrm{OH}$-recycling mechanisms for isoprene photo-oxidation are considered here, however (Peeters et al., 2009; Crounse et al., 2011). Furthermore, a recent report on instrumental issues suggests that the gap between actual and modeled $\mathrm{OH}$ concentrations may not be as large as originally reported in some studies (Mao et al., 2012).

\section{Supplementary material related to this article is available online at: http://www.atmos-chem-phys.net/13/ 5715/2013/acp-13-5715-2013-supplement.pdf.}

Acknowledgements. This material is based upon work supported by the National Science Foundation under Grant No. ATM-0959452. Y. J. Liu acknowledges support from the NASA Earth and Space Science Fellowship Program. We acknowledge the Thomson lab from Northwestern University for synthesis of $\beta$-IEPOX. We acknowledge Mikinori Kuwata, Ben Langford, Franz Geiger, Fabien Paulot, and Alfons Jordan for useful discussion and assistance with the experiments.

Edited by: J. N. Crowley 


\section{References}

Ammann, C., Spirig, C., Neftel, A., Steinbacher, M., Komenda, M., and Schaub, A.: Application of PTR-MS for measurements of biogenic VOC in a deciduous forest, Int. J. Mass. Spectrom., 239, 87-101, doi:10.1016/j.ijms.2004.08.012, 2004.

Aschmann, S. M. and Atkinson, R.: Formation yields of methyl vinyl ketone and methacrolein from the gas-phase reaction of $\mathrm{O}_{3}$ with isoprene, Environ. Sci. Technol., 28, 1539-1542, doi:10.1021/es00057a025, 1994.

Atkinson, R., Baulch, D. L., Cox, R. A., Crowley, J. N., Hampson, R. F., Hynes, R. G., Jenkin, M. E., Rossi, M. J., Troe, J., and IUPAC Subcommittee: Evaluated kinetic and photochemical data for atmospheric chemistry: Volume II - gas phase reactions of organic species, Atmos. Chem. Phys., 6, 3625-4055, doi:10.5194/acp-6-3625-2006, 2006.

Benkelberg, H. J., Boge, O., Seuwen, R., and Warneck, P.: Product distributions from the $\mathrm{OH}$ radical-induced oxidation of but-1-ene, methyl-substituted but-1-enes and isoprene in $\mathrm{NO}_{\mathrm{x}}$-free air, Phys. Chem. Chem. Phys., 2, 4029-4039, doi:10.1039/b002053m, 2000.

Blake, R. S., Wyche, K. P., Ellis, A. M., and Monks, P. S.: Chemical ionization reaction time-of-flight mass spectrometry: Multireagent analysis for determination of trace gas composition, Int. J. Mass. Spectrom., 254, 85-93, doi:10.1016/j.ijms.2006.05.021, 2006.

Blake, R. S., Monks, P. S., and Ellis, A. M.: Proton-transfer reaction mass spectrometry, Chem. Rev., 109, 861-896, doi:10.1021/cr800364q, 2009.

Butler, T. M., Taraborrelli, D., Brühl, C., Fischer, H., Harder, H., Martinez, M., Williams, J., Lawrence, M. G., and Lelieveld, J.: Improved simulation of isoprene oxidation chemistry with the ECHAM5/MESSy chemistry-climate model: lessons from the GABRIEL airborne field campaign, Atmos. Chem. Phys., 8, 4529-4546, doi:10.5194/acp-8-4529-2008, 2008.

Carter, W. P. L., Cocker Iii, D. R., Fitz, D. R., Malkina, I. L., Bumiller, K., Sauer, C. G., Pisano, J. T., Bufalino, C., and Song, C.: A new environmental chamber for evaluation of gas-phase chemical mechanisms and secondary aerosol formation, Atmos. Environ., 39, 7768-7788, doi:10.1016/j.atmosenv.2005.08.040, 2005.

Chen, Q., Liu, Y. J., Donahue, N. M., Shilling, J. E., and Martin, S. T.: Particle-phase chemistry of secondary organic material: modeled compared to measured O:C and $\mathrm{H}: \mathrm{C}$ elemental ratios provide constraints, Environ. Sci. Technol., 45, 4763-4770, doi:10.1021/es104398s, 2011.

Cox, R. A., Munk, J., Nielsen, O. J., Pagsberg, P., and Ratajczak, E.: Ultraviolet absorption spectra and kinetics of acetonyl and acetonylperoxy radicals, Chem. Phys. Lett., 173, 206-210, doi:10.1016/0009-2614(90)80079-s, 1990.

Crounse, J. D., Paulot, F., Kjaergaard, H. G., and Wennberg, P. O.: Peroxy radical isomerization in the oxidation of isoprene, Phys. Chem. Chem. Phys., 13, 13607-13613, doi:10.1039/c1cp21330j, 2011.

da Silva, G., Graham, C., and Wang, Z. F.: Unimolecular betahydroxyperoxy radical decomposition with $\mathrm{OH}$ recycling in the photochemical oxidation of isoprene, Environ. Sci. Technol., 44, 250-256, doi:10.1021/es900924d, 2010.

de Gouw, J. and Warneke, C.: Measurements of volatile organic compounds in the earths atmosphere using proton-transferreaction mass spectrometry, Mass. Spectrom. Rev., 26, 223-257, doi:10.1002/mas.20119, 2007.

Dillon, T. J. and Crowley, J. N.: Direct detection of OH formation in the reactions of $\mathrm{HO}_{2}$ with $\mathrm{CH}_{3} \mathrm{C}(\mathrm{O}) \mathrm{O}_{2}$ and other substituted peroxy radicals, Atmos. Chem. Phys., 8, 4877-4889, doi:10.5194/acp-8-4877-2008, 2008.

Graus, M., Muller, M., and Hansel, A.: High resolution PTRTOF: quantification and formula confirmation of VOC in real time, J. Am. Soc. Mass. Spectr., 21, 1037-1044, doi:10.1016/j.jasms.2010.02.006, 2010.

Hansel, A. and Wisthaler, A.: A method for real-time detection of PAN, PPN and MPAN in ambient air, Geophys. Res. Lett., 27, 895-898, doi:10.1029/1999g1010989, 2000.

Hasson, A. S., Tyndall, G. S., and Orlando, J. J.: A product yield study of the reaction of $\mathrm{HO}_{2}$ radicals with ethyl peroxy $\left(\mathrm{C}_{2} \mathrm{H}_{5} \mathrm{O}_{2}\right)$, acetyl peroxy $\left(\mathrm{CH}_{3} \mathrm{C}(\mathrm{O}) \mathrm{O}_{2}\right)$, and acetonyl peroxy $\left(\mathrm{CH}_{3} \mathrm{C}(\mathrm{O}) \mathrm{CH}_{2} \mathrm{O}_{2}\right)$ radicals, J. Phys. Chem. A, 108, 5979-5989, doi:10.1021/jp048873t, 2004.

Hasson, A. S., Kuwata, K. T., Arroyo, M. C., and Petersen, E. B.: Theoretical studies of the reaction of hydroperoxy radicals $\left(\mathrm{HO}_{2}\right)$ with ethyl peroxy $\left(\mathrm{CH}_{3} \mathrm{CH}_{2} \mathrm{O}_{2}\right)$, acetyl peroxy $\left(\mathrm{CH}_{3} \mathrm{C}(\mathrm{O}) \mathrm{O}_{2}\right)$, and acetonyl peroxy $\left(\mathrm{CH}_{3} \mathrm{C}(\mathrm{O}) \mathrm{CH}_{2} \mathrm{O}_{2}\right)$ radicals, J. Photoch. Photobio. A, 176, 218-230, doi:10.1016/j.jphotochem.2005.08.012, 2005.

Hewitt, C. N., Lee, J. D., MacKenzie, A. R., Barkley, M. P., Carslaw, N., Carver, G. D., Chappell, N. A., Coe, H., Collier, C., Commane, R., Davies, F., Davison, B., DiCarlo, P., Di Marco, C. F., Dorsey, J. R., Edwards, P. M., Evans, M. J., Fowler, D., Furneaux, K. L., Gallagher, M., Guenther, A., Heard, D. E., Helfter, C., Hopkins, J., Ingham, T., Irwin, M., Jones, C., Karunaharan, A., Langford, B., Lewis, A. C., Lim, S. F., MacDonald, S. M., Mahajan, A. S., Malpass, S., McFiggans, G., Mills, G., Misztal, P., Moller, S., Monks, P. S., Nemitz, E., Nicolas-Perea, V., Oetjen, H., Oram, D. E., Palmer, P. I., Phillips, G. J., Pike, R., Plane, J. M. C., Pugh, T., Pyle, J. A., Reeves, C. E., Robinson, N. H., Stewart, D., Stone, D., Whalley, L. K., and Yin, X.: Overview: oxidant and particle photochemical processes above a south-east Asian tropical rainforest (the OP3 project): introduction, rationale, location characteristics and tools, Atmos. Chem. Phys., 10, 169-199, doi:10.5194/acp-10-169-2010, 2010.

Jenkin, M. E., Saunders, S. M., and Pilling, M. J.: The tropospheric degradation of volatile organic compounds: A protocol for mechanism development, Atmos. Environ., 31, 81-104, doi:10.1016/s1352-2310(96)00105-7, 1997.

Jenkin, M. E., Boyd, A. A., and Lesclaux, R.: Peroxy radical kinetics resulting from the $\mathrm{OH}$-initiated oxidation of 1,3-butadiene, 2,3-dimethyl-1,3-butadiene and isoprene, J. Atmos. Chem., 29, 267-298, doi:10.1023/a:1005940332441, 1998.

Jenkin, M. E., Hurley, M. D., and Wallington, T. J.: Investigation of the radical product channel of the $\mathrm{CH}_{3} \mathrm{C}(\mathrm{O}) \mathrm{O}_{2}+\mathrm{HO}_{2}$ reaction in the gas phase, Phys. Chem. Chem. Phys., 9, 3149-3162, doi:10.1039/b702757e, 2007.

Jenkin, M. E., Hurley, M. D., and Wallington, T. J.: Investigation of the radical product channel of the $\mathrm{CH}_{3} \mathrm{C}(\mathrm{O}) \mathrm{CH}_{2} \mathrm{O}_{2}+\mathrm{HO}_{2}$ reaction in the gas phase, Phys. Chem. Chem. Phys., 10, 42744280, doi:10.1039/b802898b, 2008.

Jordan, A., Haidacher, S., Hanel, G., Hartungen, E., Herbig, J., Märk, L., Schottkowsky, R., Seehauser, H., Sulzer, P., and Märk, T. D.: An online ultra-high sensitivity proton-transfer-reaction mass-spectrometer combined with switchable reagent ion capa- 
bility (PTR + SRI - MS), Int. J. Mass. Spectrom., 286, 32-38, doi:10.1016/j.ijms.2009.06.006, 2009a.

Jordan, A., Haidacher, S., Hanel, G., Hartungen, E., Märk, L., Seehauser, H., Schottkowsky, R., Sulzer, P., and Märk, T. D.: A high resolution and high sensitivity proton-transfer-reaction time-offlight mass spectrometer (PTR-TOF-MS), Int. J. Mass. Spectrom., 286, 122-128, doi:10.1016/j.ijms.2009.07.005, 2009b.

Karl, M., Dorn, H. P., Holland, F., Koppmann, R., Poppe, D., Rupp, L., Schaub, A., and Wahner, A.: Product study of the reaction of $\mathrm{OH}$ radicals with isoprene in the atmosphere simulation chamber SAPHIR, J. Atmos. Chem., 55, 167-187, doi:10.1007/s10874006-9034-x, 2006.

Karl, T., Hansel, A., Cappellin, L., Kaser, L., Herdlinger-Blatt, I., and Jud, W.: Selective measurements of isoprene and 2methyl-3-buten-2-ol based on $\mathrm{NO}^{+}$ionization mass spectrometry, Atmos. Chem. Phys., 12, 11877-11884, doi:10.5194/acp12-11877-2012, 2012.

King, S. M., Rosenoern, T., Shilling, J. E., Chen, Q., and Martin, S. T.: Increased cloud activation potential of secondary organic aerosol for atmospheric mass loadings, Atmos. Chem. Phys., 9, 2959-2971, doi:10.5194/acp-9-2959-2009, 2009.

King, S. M., Rosenoern, T., Shilling, J. E., Chen, Q., Wang, Z., Biskos, G., McKinney, K. A., Pöschl, U., and Martin, S. T.: Cloud droplet activation of mixed organic-sulfate particles produced by the photooxidation of isoprene, Atmos. Chem. Phys., 10, 3953-3964, doi:10.5194/acp-10-3953-2010, 2010.

Lee, W., Baasandorj, M., Stevens, P. S., and Hites, R. A.: Monitoring $\mathrm{OH}$-initiated oxidation kinetics of isoprene and its products using online mass spectrometry, Environ. Sci. Technol., 39, 1030-1036, doi:10.1021/es049438f, 2005.

Lelieveld, J., Butler, T. M., Crowley, J. N., Dillon, T. J., Fischer, H., Ganzeveld, L., Harder, H., Lawrence, M. G., Martinez, M., Taraborrelli, D., and Williams, J.: Atmospheric oxidation capacity sustained by a tropical forest, Nature, 452, 737-740, doi:10.1038/nature06870, 2008.

Lightfoot, P. D., Cox, R. A., Crowley, J. N., Destriau, M., Hayman, G. D., Jenkin, M. E., Moortgat, G. K., and Zabel, F.: Organic peroxy radicals: Kinetics, spectroscopy and tropospheric chemistry, Atmos. Environ. A-Gen., 26, 1805-1961, doi:10.1016/09601686(92)90423-i, 1992.

Mao, J., Ren, X., Zhang, L., Van Duin, D. M., Cohen, R. C., Park, J.-H., Goldstein, A. H., Paulot, F., Beaver, M. R., Crounse, J. D., Wennberg, P. O., DiGangi, J. P., Henry, S. B., Keutsch, F. N., Park, C., Schade, G. W., Wolfe, G. M., Thornton, J. A., and Brune, W. H.: Insights into hydroxyl measurements and atmospheric oxidation in a California forest, Atmos. Chem. Phys., 12, 8009-8020, doi:10.5194/acp-12-8009-2012, 2012.

McKinney, K. A., Lee, B. H., Vasta, A., Pho, T. V., and Munger, J. W.: Emissions of isoprenoids and oxygenated biogenic volatile organic compounds from a New England mixed forest, Atmos. Chem. Phys., 11, 4807-4831, doi:10.5194/acp-11-4807-2011, 2011.

McMurry, P. H. and Grosjean, D.: Gas and aerosol wall losses in Teflon film smog chambers, Environ. Sci. Technol., 19, 11761182, doi:10.1021/es00142a006, 1985.

Miyoshi, A., Hatakeyama, S., and Washida, N.: OH radicalinitiated photooxidation of isoprene - an estimate of global CO production, J. Geophys. Res., 99, 18779-18787, doi:10.1029/94jd01334, 1994.
Müller, M., Graus, M., Ruuskanen, T. M., Schnitzhofer, R., Bamberger, I., Kaser, L., Titzmann, T., Hörtnagl, L., Wohlfahrt, G., Karl, T., and Hansel, A.: First eddy covariance flux measurements by PTR-TOF, Atmos. Meas. Tech., 3, 387-395, doi:10.5194/amt-3-387-2010, 2010.

Navarro, M. A., Dusanter, S., Hites, R. A., and Stevens, P. S.: Radical dependence of the yields of methacrolein and methyl vinyl ketone from the $\mathrm{OH}$-Initiated oxidation of isoprene under $\mathrm{NO}_{\mathrm{x}}$-free conditions, Environ. Sci. Technol., 45, 923-929, doi:10.1021/es103147w, 2011.

Pankow, J. F. and Asher, W. E.: SIMPOL.1: a simple group contribution method for predicting vapor pressures and enthalpies of vaporization of multifunctional organic compounds, Atmos. Chem. Phys., 8, 2773-2796, doi:10.5194/acp-8-27732008, 2008.

Paulot, F., Crounse, J. D., Kjaergaard, H. G., Kurten, A., St Clair, J. M., Seinfeld, J. H., and Wennberg, P. O.: Unexpected epoxide formation in the gas-phase photooxidation of isoprene, Science, 325, 730-733, doi:10.1126/science.1172910, 2009.

Paulson, S. E., Flagan, R. C., and Seinfeld, J. H.: Atmospheric photooxidation of isoprene part I: The hydroxyl radical and ground state atomic oxygen reactions, Int. J. Chem. Kinet., 24, 79-101, doi:10.1002/kin.550240109, 1992.

Peeters, J. and Muller, J.-F.: $\mathrm{HO}_{\mathrm{x}}$ radical regeneration in isoprene oxidation via peroxy radical isomerisations. II: experimental evidence and global impact, Phys. Chem. Chem. Phys., 12, 14227 14235, doi:10.1039/c0cp00811g, 2010.

Peeters, J., Nguyen, T. L., and Vereecken, L.: $\mathrm{HO}_{\mathrm{x}}$ radical regeneration in the oxidation of isoprene, Phys. Chem. Chem. Phys., 11, 5935-5939, doi:10.1039/b908511d, 2009.

Poisson, N., Kanakidou, M., and Crutzen, P. J.: Impact of non-methane hydrocarbons on tropospheric chemistry and the oxidizing power of the global troposphere: 3dimensional modelling results, J. Atmos. Chem., 36, 157-230, doi:10.1023/a:1006300616544, 2000.

Rohrer, F., Bohn, B., Brauers, T., Brüning, D., Johnen, F.-J., Wahner, A., and Kleffmann, J.: Characterisation of the photolytic HONO-source in the atmosphere simulation chamber SAPHIR, Atmos. Chem. Phys., 5, 2189-2201, doi:10.5194/acp-5-21892005, 2005.

Ruppert, L. and Becker, K. H.: A product study of the $\mathrm{OH}$ radicalinitiated oxidation of isoprene: formation of $\mathrm{C}_{5}$-unsaturated diols, Atmos. Environ., 34, 1529-1542, doi:10.1016/s13522310(99)00408-2, 2000.

Saunders, S. M., Jenkin, M. E., Derwent, R. G., and Pilling, M. J.: Protocol for the development of the Master Chemical Mechanism, MCM v3 (Part A): tropospheric degradation of nonaromatic volatile organic compounds, Atmos. Chem. Phys., 3, 161-180, doi:10.5194/acp-3-161-2003, 2003.

Shilling, J. E., Chen, Q., King, S. M., Rosenoern, T., Kroll, J. H., Worsnop, D. R., DeCarlo, P. F., Aiken, A. C., Sueper, D., Jimenez, J. L., and Martin, S. T.: Loading-dependent elemental composition of $\alpha$-pinene SOA particles, Atmos. Chem. Phys., 9, 771-782, doi:10.5194/acp-9-771-2009, 2009.

Smith, D., and Španěl, P.: Selected ion flow tube mass spectrometry (SIFT-MS) for on-line trace gas analysis, Mass. Spectrom. Rev., 24, 661-700, doi:10.1002/mas.20033, 2005.

Španěl, P., Ji, Y., and Smith, D.: SIFT studies of the reactions of $\mathrm{H}_{3} \mathrm{O}^{+}, \mathrm{NO}^{+}$and $\mathrm{O}_{2}^{+}$with a series of aldehydes and ketones, 
Int. J. Mass. Spectrom., 165-166, 25-37, doi:10.1016/s01681176(97)00166-3, 1997.

Španěl, P., Doren, J. M. V., and Smith, D.: A selected ion flow tube study of the reactions of $\mathrm{H}_{3} \mathrm{O}^{+}, \mathrm{NO}^{+}$, and $\mathrm{O}_{2}^{+}$with saturated and unsaturated aldehydes and subsequent hydration of the product ions, Int. J. Mass. Spectrom., 213, 163-176, doi:10.1016/s1387-3806(01)00531-0, 2002.

Sprengnether, M., Demerjian, K. L., Donahue, N. M., and Anderson, J. G.: Product analysis of the $\mathrm{OH}$ oxidation of isoprene and 1,3-butadiene in the presence of NO, J. Geophys. Res., 107, 4268, doi:10.1029/2001jd000716, 2002.

Stone, D., Evans, M. J., Edwards, P. M., Commane, R., Ingham, T., Rickard, A. R., Brookes, D. M., Hopkins, J., Leigh, R. J., Lewis, A. C., Monks, P. S., Oram, D., Reeves, C. E., Stewart, D., and Heard, D. E.: Isoprene oxidation mechanisms: measurements and modelling of $\mathrm{OH}$ and $\mathrm{HO}_{2}$ over a South-East Asian tropical rainforest during the OP3 field campaign, Atmos. Chem. Phys., 11, 6749-6771, doi:10.5194/acp-11-6749-2011, 2011.

Sulbaek Andersen, M. P., Hurley, M. D., Wallington, T. J., Ball, J. C., Martin, J. W., Ellis, D. A., and Mabury, S. A.: Atmospheric chemistry of $\mathrm{C}_{2} \mathrm{~F}_{5} \mathrm{CHO}$ : mechanism of the $\mathrm{C}_{2} \mathrm{~F}_{5} \mathrm{C}(\mathrm{O}) \mathrm{O}_{2}+\mathrm{HO}_{2}$ reaction, Chem. Phys. Lett., 381, 14-21, doi:10.1016/j.cplett.2003.09.085, 2003.
Taraborrelli, D., Lawrence, M. G., Crowley, J. N., Dillon, T. J., Gromov, S., Grosz, C. B. M., Vereecken, L., and Lelieveld, J.: Hydroxyl radical buffered by isoprene oxidation over tropical forests, Nat. Geosci., 5, 190-193, doi:10.1038/ngeo1405, 2012.

Tuazon, E. C. and Atkinson, R.: A product study of the gas-phase reaction of isoprene with the $\mathrm{OH}$ radical in the presence of $\mathrm{NO}_{\mathrm{x}}$, Int. J. Chem. Kinet., 22, 1221-1236, doi:10.1002/kin.550221202, 1990.

Wallington, T. J., Dagaut, P., and Kurylo, M. J.: UV absorption cross sections and reaction kinetics and mechanisms for peroxy radicals in the gas phase, Chem. Rev., 92, 667-710, doi:10.1021/cr00012a008, 1992.

Zhang, Z., Lin, Y.-H., Zhang, H., Surratt, J. D., Ball, L. M., and Gold, A.: Technical Note: Synthesis of isoprene atmospheric oxidation products: isomeric epoxydiols and the rearrangement products cis- and trans-3-methyl-3,4-dihydroxytetrahydrofuran, Atmos. Chem. Phys., 12, 8529-8535, doi:10.5194/acp-12-85292012, 2012.

Zhao, J. and Zhang, R.: Proton transfer reaction rate constants between hydronium ion $\left(\mathrm{H}_{3} \mathrm{O}^{+}\right)$and volatile organic compounds, Atmos. Environ., 38, 2177-2185, doi:10.1016/j.atmosenv.2004.01.019, 2004. 